\title{
Analysis of volatile compounds from Iberian hams: a review
}

\author{
By M. Narváez-Rivas, E. Gallardo and M. León-Camacho*
}

\author{
Food Characterization and Quality Department. Instituto de la Grasa (C.S.I.C.). \\ Avda. Padre García Tejero, 4. 41012 Seville, Spain. \\ *Corresponding author: mleon @ cica.es
}

\begin{abstract}
RESUMEN
Análisis de los compuestos volátiles del jamón ibérico: revisión

En este artículo se proporciona información sobre el estudio de los compuestos volátiles del jamón ibérico tanto fresco como curado. Se presentan los diferentes compuestos volátiles identificados por distintos autores. Además, se evalúan los métodos analíticos que han sido utilizados para determinar dichos compuestos volátiles en este tipo de muestras. Todos los compuestos identificados y descritos en esta revisión (un total de 411 compuestos volátiles) han sido agrupados en diversas tablas de acuerdo a las diferentes familias a que pertenecen: hidrocarburos, aldehídos, cetonas, alcoholes, ésteres y éteres, lactonas, terpenos, compuestos halogenados, compuestos nitrogenados, compuestos de azufre y ácidos carboxílicos. Debido a la complejidad de este estudio, la presente revisión puede ser muy útil en investigaciones posteriores.
\end{abstract}

PALABRAS-CLAVE: Cerdo ibérico - Compuestos volatiles - Cromatografía gaseosa - Jamón - Proceso de curado.

\section{SUMMARY}

Analysis of volatile compounds from Iberian hams: a review

This article provides information on the study of the volatile compounds in raw and dry-cured Iberian hams. Different volatile compounds are identified and studies carried out by different authors are presented. This article reviews the analytical methods that have been used to determine the different volatiles of these samples. Furthermore, all volatile compounds identified (a total of 411 volatiles) have been collected in several tables according to different series of compounds: hydrocarbons, aldehydes, ketones, alcohols, esters and ethers, lactones, terpenes and chloride compounds, nitrogenous compounds, sulfur compounds and carboxylic acids. This review can be useful in subsequent research due to the complexity of the study.

KEY-WORDS:Dry-curedProcess-GasChromatographyHams - Iberian Pigs - Review - Volatile compounds

\section{INTRODUCTION}

Dry-cured Iberian ham is an expensive meat product with an extraordinary consumer acceptance in Spain and around the world. Consumer preference highly depends on the sensory quality of slices, which is mainly determined by aroma, taste and texture. The main factors that impact the characteristic intense flavor of this product are the meat quality as well as the conditions of the ripening process. The factors that affect the raw meat characteristics are the rearing system, mainly during the final fattening period, the age of the animals and pig genotype (Dirinck et al., 1997; Sabio et al., 1998; Jurado et al., 2007; Ramírez and Cava, 2007). However, the fattening diet of animals is the factor that determines the ham prices on the market. According to the feed type, there are three different types of dry-cured Iberian ham: "Montanera" (fed only on acorns and pasture), "Recebo" (fed on acorns, pasture and concentrated feed) and "Cebo" (fed on concentrated feed), the first being the most expensive. The production of Iberian pig is deeply bounded to the Mediterranean ecosystem. The outdoor rearing system has a positive image for consumers since it is associated with an increase in animal welfare, reduced environmental impact and protection for a traditional production system (Rey et al., 2006).

Traditional dry-curing of this kind of hams is a long process, over 24-36 months, in which humidity and temperature are controlled (Flores and Toldrá, 1993). During this period, raw hams undergo four stages: salting with dry salt, washing, post-salting for salt equalization and ripening-drying (in a cellar) (Flores and Toldrá, 1993). In the salting and postsalting stages, the hams are kept at low temperatures to reduce the risk of bacterial spoilage. However, in the ripening-drying stage, they are left to mature under environmental conditions (temperatures range from 20 to $35^{\circ} \mathrm{C}$ ).

It has been postulated that chemical or enzymatic reactions such as lipolysis, chemical or enzymatic oxidation, proteolysis, Strecker degradation and Maillard reactions are present in the dry-curing process of Iberian hams (Narváez-Rivas et al., 2007), and that these chemical processes are the origin of volatile compounds (Toldrá, 1998; Toldrá et al., 2009) which are especially generated in the latest stages (Flores, 1997).

A large number of volatile compounds have been reported in dry-cured Iberian hams by several authors. Among these compounds, there are hydrocarbons, 
aldehydes, ketones, alcohols, acids, esters, terpenes, sulphur compounds, nitrogenous compounds and others. However, only a limited number of volatile compounds actually contribute to the overall ham aroma, such as aldehydes and ketones (Carrapiso et al., 2002). A detailed study of the volatile compounds will be carried out in this review.

All the information possible concerning volatile compounds of raw and dry-cured ham is necessary in order to monitor the quality of the flavor and to provide quality control for these processed products.

Several techniques have been used to isolate the volatile compounds from Iberian hams which will be explained in this review, along with the procedures employed for their separation, identification and quantification.

\section{ANALYSIS OF VOLATILE COMPOUNDS}

The determination of volatile compounds is complex due to different factors, such as the high number of compounds, differences in volatility and the great amount of functional groups. The different techniques that exist lead to the collections of volatile profiles, which may differ for the same product, depending on the extractive power and selectivity of the technique with respect to one type of compound or another. Furthermore, food aroma research is difficult due to the ability of volatile compounds to bind to the solid matrix of food and to their degree of ease in releasing from it. This aspect is particularly important in Iberian ham, since the ham does not lose practically any of its original structure during the dry-curing process due to the presence of salt; therefore this is a very complex matrix with a wide range of components that interact with each other or with the volatile compounds and prevent a full extraction process.

The profile of volatile compounds from Iberian hams has been used to differentiate different types of pig feedings (Narváez-Rivas et al., 2010b; Timón et al., 2002; Narváez-Rivas et al., 2011), genotypes (Iberian x Duroc) (Ramírez and Cava, 2007) and breed types (French, Iberian and White) (SánchezPeña et al., 2005), to study the effect of salt content and processing conditions (Andrés et al., 2007), and to study the length of the process (Dumont and Ada, 1972).

\subsection{Sampling}

The analysis of volatile compounds in dry-cured Iberian hams has been carried out using samples taken from different anatomical locations. Several authors (Sabio et al., 1998; Ramírez and Cava,

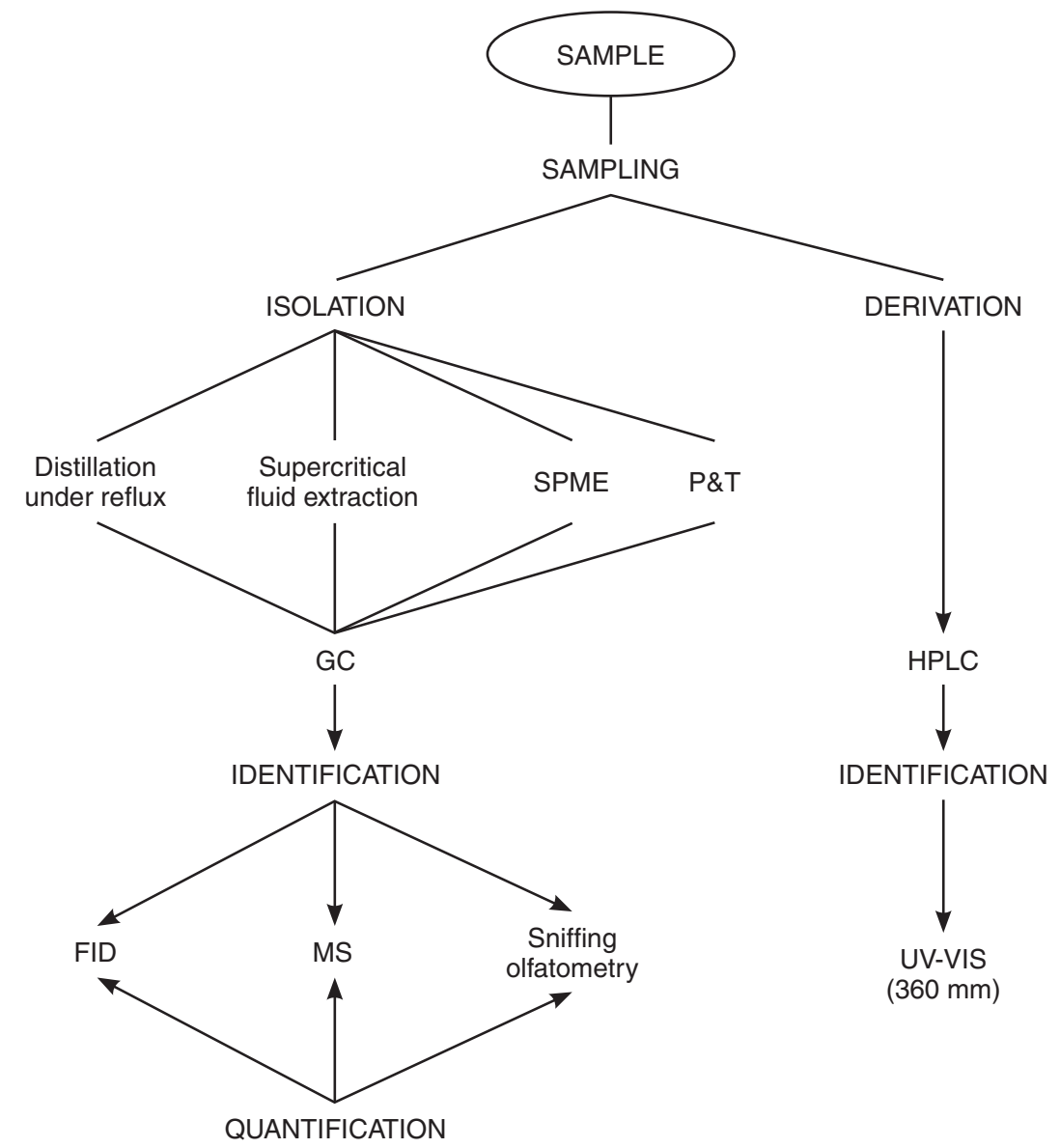

Figure 1

Summarized scheme of different steps and techniques used in the analysis of volatile compounds. 
2007; Carrapiso et al., 2002; López, et al., 1992; Timón et al., 1998) have used bicep femoris muscle for this analysis. Others (García et al., 1991; Jurado et al., 2009) used semi-membranosous and bicep femoris muscles. García-González et al. (2008) and Sánchez-Peña et al. (2005) analyzed the part located along and behind the femur, composed essentially of subcutaneous fat and bicep femoris, semi-membranosous and semitendinosous muscles. In other studies, the muscles selected were only semi-membranosous and semi-tendinosous (NarváezRivas et al., 2010a, 2010b), which were minced before analysis. In addition, the volatile profile of subcutaneous (Timón et al., 2002; Narváez-Rivas et al., 2010a; Timón et al., 2001) and intermuscular fat (Timón et al., 2001) from dry-cured Iberian ham has been the object of study (Narváez-Rivas et al., 2011).

Samples from ham have been taken using different procedures. In some cases, a cylindrical stainless steel tool was used to extract a sample along the thickness and this was then cut into small slices (Sánchez-Peña et al., 2005) or ground (Jurado et al., 2009). Several authors have carried out the analysis by cutting a portion of ham (muscle, fat or muscle and fat), which was blended and minced (Sabio et al., 1998; Ramírez and Cava, 2007; Carrapiso et al., 2002; Narváez-Rivas et al., 2011; López et al., 1992; Timón et al., 1998; García et al., 1991; García-González et al., 2008). Instead of cutting a portion of ham, slices have been taken, minced and mixed (Narváez-Rivas et al., 2010b; Narváez-Rivas et al., 2010a; Ruiz et al., 1999) or directly analyzed (Ruiz et al., 1998). On the other hand, a sample of fat has been taken and directly analyzed, without subsequent treatment (Timón et al., 2002; Timón et al., 2001). There are techniques that avoid preparation of the sample and allow a direct extraction of volatiles from hams (Andrés et al., 2007; Ruiz et al., 2001; Andrés et al., 2002), as we will see later.

Ham is a solid and heterogeneous material, so the volatile compounds found can be different depending on the part of the ham sampled and how the sampling is carried out. If sampling is carried out not only in different parts of the ham but also with different procedures (cut in slices, minced, etc.), the results may vary.

\subsection{Isolation}

Certainly, the key the complexity of the analysis of volatile compounds is in their isolation and preconcentration prior to the gas-chromatographic analysis. The low level of concentration of these compounds, the wide distribution of vapor pressures and the large difference in structures and functional groups have motivated the development of the different techniques of isolation and preconcentration of these compounds, which has been directed towards making the procedure of analysis as accurate, reproducible and repetitive as possible.
Several methods have been developed for volatile compound extraction and much of them have been used to study the Iberian ham. These techniques are the aim of this section.

\subsubsection{Distillation under high vacuum}

The first methods used for the recovery of volatile compounds consisted of the use of distillation followed by extraction with organic solvents (dichloromethane, carbon disulphide).

In 1991, García et al. (1991) used the method of Dumont and Ada (1972), in which the sample was transferred to a flask that was connected to an icetrap cooled with liquid nitrogen and maintained at low pressure 5 hours. After distillation, the trap was carefully washed using distillate water. Then, the eluted fraction was extracted with dichloromethane and the resulting extract was concentrated with a column. The principal problem of this technique arises from the interference that exists between the solvent front and the compounds that elute with it, since the solvent means more than $99 \%$ of the sample, in spite of its low response in flame ionization detection system (saturation of column stationary phase). This method is lengthy and involves a great deal of sample handling, and for these reasons, other methods that are not so long and tedious have been more widely used to study volatiles from Iberian hams. Furthermore, in addition to odorant compounds, the utilization of organic solvent in the extraction can carry other food components, particularly lipids, which may make subsequent operations difficult. On the other hand, these solvents promote a selective extraction of volatiles depending on the polarity of the solvent and volatiles.

\subsubsection{Supercritical fluid extraction}

Timón et al. (1998) obtained aroma extracts from Iberian ham using a supercritical fluid (carbon dioxide) as the extraction technique for volatiles. They used a Hewlett-Packard 7680A supercritical fluid extractor. The extraction was carried out for $15 \mathrm{~min}$. Different temperatures $\left(40-60^{\circ} \mathrm{C}\right)$ and pressures $(77-218 \mathrm{~atm})$ were tested, and finally, it was concluded that larger numbers and higher concentrations of volatile compounds were achieved at $40^{\circ} \mathrm{C}$ and at $91 \mathrm{~atm}$. It has been reported that flavor compounds obtained by this method showed a great similarity to the original source (Merkle and Larick, 1994). This helps to reduce or eliminate the use of halogenated solvents and to extract samples more quickly and efficiently than the distillation under reflux method. Besides, this technique allows for the analysis of thermally unstable samples.

\subsubsection{Solid-phase microextraction}

The static headspace solid-phase microextraction (SPME) technique is used in the analysis of volatile 
compounds when the number of compounds is not too large and they are at a considerable concentration. However, the employment of SPME improves the chromatographic analysis, since by using a fiber of absorbent material, a sample pre-concentration takes place. The compounds present in the headspace are absorbed by this fiber and the volatile compounds released from the bounded phase to reach equilibrium with the vapor phase. Strictly speaking, the technique in question cannot be considered as a static headspace. Nevertheless, SPME can be classified in this group of techniques since there is no steam distillation and it is carried out in a closed system.

The adsorption SPME technique, developed by Arthur et al. (1990, 1992), is one of the most commonly used techniques to isolate volatiles from Iberian hams (Ramírez and Cava, 2007; Toldrá, 1998; Sánchez-Peña et al., 2005; Andrés et al., 2007; Jurado et al., 2009; García-González et al., 2008; Ruiz et al., 2001; Andrés et al., 2002; Andrade et al., 2009; Zhang and Pawliszyn, 1993), since it is solvent free, inexpensive, easy to use and relatively fast (Andrade et al., 2009). SPME involves absorbing the analyte from the sample onto a modified solid support (fiber). Samples are placed into glass vials tightly capped with a septum, in which the SPME fiber, previously preconditioned at a high temperature, is inserted and then exposed to the headspace. During this process, two equilibria should be reached by the analytes: between the matrix and the headspace and between the headspace and the coating of the fiber (Ruiz et al., 1999). To reduce the equilibration time, agitation and heating have been proposed (Ruiz et al., 1999). Therefore, the extraction is carried out in an oven to ensure a homogeneous temperature for sample and headspace. When the process is completed, the fiber is inserted into the injector port of the gas chromatograph and the analytes are then desorbed by thermal means. The fibers chosen for the analysis of volatiles from Iberian hams are coated with divinylbenzene-carboxen-poly(dimethylsiloxane) (DVB/CAR/PDMS) (Ramírez and Cava, 2007; Sánchez-Peña et al., 2005; García-González et al., 2008) or carboxen-poly(dimethylsiloxane) (CAR/ PDMS) (Andrés et al., 2007; Jurado et al., 2009; Ruiz et al., 2001; Andrés et al., 2002; Andrade et al., 2009), because of their high sensitivity and varying thicknesses of the fiber used, which have been measured at 50/30 (Ramírez and Cava, 2007; Sánchez-Peña et al., 2005), 75 (Andrés et al., 2007; Jurado et al., 2009; Ruiz et al., 2001) and $100 \mu \mathrm{m}$ (Andrade et al., 2009). A higher number of volatile compounds was found using CAR/PDMS as fiber (between 61 and 107 volatiles), but there is no relation between the thickness of the fiber and the number of volatiles and the highest number of volatiles (107 compounds) was found when using a thickness of $75 \mu \mathrm{m}$ (Andrés et al., 2002) and the lowest (30 compounds) was found with a thickness of $50 / 30 \mu \mathrm{m}$ (Sánchez-Peña et al., 2005). This is one of the techniques that require less sample handling and thus less interference in the collection of volatile compounds.
SPME has been coupled to a direct extraction device (DED) (Andrés et al., 2007; Ruiz et al., 2001; Andrés et al., 2002), avoiding preparation of the sample. The operating mode involves placing the needle of the SPME holder into the DED, and thereafter this is introduced into the core of ham the without damaging the fiber and avoiding physical sampling of the hams (Ruiz et al., 2001).

One of the advantages of static headspace sampling is the ability to analyze a sample for low molecular weight volatiles without the presence of a solvent peak. Besides, this technique can be easily automated which provides increased repeatability over manual approaches. Other additional advantages of the static headspace technique are relatively low cost per analysis, simple sample preparation, and the elimination of reagents (Wampler, 2002).

The main limitation of SPME is the relatively small amount of sorbent material available on the fiber. Another disadvantage related to this technique is that, for very low levels of analyte concentration in the original sample material, it may have a lack of sensitivity required for the determination, since the concentration in the headspace is in equilibrium with the sample matrix and only a portion of the headspace is withdrawn and transferred. This can be improved by elevating the temperature of the sample to increase the volatility of the analytes. Nevertheless, most static headspace instruments have the capability of heating samples to only about $150^{\circ} \mathrm{C}$, which limits the detection of analytes with higher boiling points. Finally, reproducibility depends on analyzing a sample after it has reached equilibrium, and the time required to achieve this point may, especially for less volatile compounds, be a drawback for some analyses (Wampler, 2002).

\subsubsection{Dynamic headspace (Purge and trap)}

In dynamic headspace (DHS), the sample is purged (swept) with an inert gas, such as nitrogen or helium, which strips aroma constituents from the sample. The volatiles in the purge gas must then be trapped from the gas stream.

When an inert carrier gas is bubbled through the sample, forcing the release of the volatiles from the matrix, the technique is also referred to as "purge and trap". This technique has certainly been the most commonly used in the analysis of volatile compounds by various authors, although many authors think that volatiles obtained by DHS better represent the real volatile fraction that reaches the human receptors when a sample is smelt.

The volatile compounds from Iberian ham have also been isolated by the purge and trap technique and adsorbed in a capillary trap (Sabio et al., 1998; Carrapiso et al., 2002; Narváez-Rivas et al., 2010b; Timón et al., 2002; Narváez-Rivas et al., 2011; Dumont and Ada, 1972; López et al., 1992; Narváez-Rivas et al., 2010a; Timón et al., 2001). In this method, the sample is introduced into a dynamic headspace vial which is thermostated for a time to increase the fugacity of volatile compounds, and subsequently, for a few 
minutes the volatile substances are purged with purified helium and adsorbed into a capillary Tenax trap held at a low temperature with liquid nitrogen. After adsorption onto a sorbent, the trapped compounds are desorbed by heating and then cryofocused at the head of the gas chromatograph-column (Pillonel et al., 2002). The analytes can also be eluted with a solvent (Burger and Munro, 1987; Olafsdottir et al., 1985) but recovery is not always satisfactory (Boren et al., 1985) and is difficult to automate. However, thermal desorption shows the following advantages: analysis of $100 \%$ of the trap content, no solvent peak, no waste and no contamination from the solvent (Pillonel et al., 2002).

One of the main problems of dynamic headspace is the adsorption of water in the trap, which can damage the MS-detector and induce a modification of the spectrum, rendering identification difficult. So, it is necessary to use one or a combination of the following solutions: dry purge, condensation of water in a cold water trap (condenser), hygroscopic trap and drying of the sample, and permeation (Nafion membrane) (Pillonel et al., 2002).

All authors that have used this technique to isolate the volatiles from Iberian hams have used an automatic Purge and Trap concentrator, in which a thermal desorption mode is used.

The use of different temperatures and times in each step has shown differences among the studies. For example, using the same kind of sample (bicep femoris muscle), Sabio et al. (1998) and López et al. (1992) extracted a different number of volatile compounds (88 and 64 respectively), which can be due to the use of different temperatures and times in the purge step $\left(35^{\circ} \mathrm{C}\right.$ for $1 \mathrm{~h}$ and $29^{\circ} \mathrm{C}$ for $45 \mathrm{~min}$, respectively).

Dynamic headspace techniques offer many of the same advantages of static headspace, including elimination of the solvent peak, analysis of just the volatiles, automation, and easy sample preparation. In addition, the trapping stage of the analysis offers increased sensitivity, permitting the analysis of volatiles at parts per billion ( $p p b$ ) levels routinely. Furthermore, sorbents offer some selectivity within the range of volatiles collected, so it may be possible to select a combination of sorbent and temperature which permits the collection and concentration of specific analytes while venting others, thus simplifying the analysis (Wampler, 2002).

On the other hand, purge-and-trap instrumentation is more complex since it requires the monitoring of several steps, and may be more expensive than others (Wampler, 2002). The sources of error in purge and trap are purge time, trap drying, trap transfer, trap temperature, capping material and sample storage (Washall and Wampler, 1990).

\subsection{Gas chromatography}

Once the volatile compounds have been isolated their matrix, their analysis is carried out by gas chromatography (GC) using a fused silica capillary column. Different columns (low and high polarity) have been used in this analysis, and their properties can be seen in Table 1. The stationary phase of the low polar

Table 1

Different columns used in the analysis of volatile compounds of dry-cured lberian hams

\begin{tabular}{|c|c|c|c|c|c|c|}
\hline Column & Stationary phase & Polarity & $\begin{array}{l}\text { Length } \\
\text { (m) }\end{array}$ & $\begin{array}{l}\text { Internal } \\
\text { diameter } \\
(\mathrm{mm})\end{array}$ & $\begin{array}{c}\text { Film } \\
\text { thickness } \\
(\mu \mathrm{m})\end{array}$ & References \\
\hline $\begin{array}{l}\text { HP-5 } \\
\text { (Hewlett-Packard) }\end{array}$ & (5\%-Phenyl)-methylpolysiloxane & Low polar & 50 & 0.32 & 1.05 & $3,8,12,16,18,19,20,21,22$ \\
\hline $\begin{array}{l}\text { HP-5 } \\
\text { (Hewlett-Packard) }\end{array}$ & (5\%-Phenyl)-methylpolysiloxane & Low polar & 50 & 0.32 & 0.52 & 10 \\
\hline $\begin{array}{l}\text { HP-FFAP } \\
\text { (Hewlett-Packard) }\end{array}$ & $\begin{array}{l}\text { Nitroterephthalic acid modified } \\
\text { polyethylene glycol }\end{array}$ & High polarity & 30 & 0.32 & 0.25 & $3,21,22$ \\
\hline $\begin{array}{l}\text { HP-FFAP } \\
\text { (Hewlett-Packard) }\end{array}$ & $\begin{array}{l}\text { Nitroterephthalic acid modified } \\
\text { polyethylene glycol }\end{array}$ & High polarity & 50 & 0.25 & 0.25 & 9 \\
\hline $\begin{array}{l}\text { DB-5 } \\
\text { (Agilent J\&W) }\end{array}$ & (5\%-Phenyl)-methylpolysiloxane & Low polar & 50 & 0.32 & 1.05 & $1,5,15$ \\
\hline $\begin{array}{l}\text { DB-WAX } \\
\text { (J\&W Scientific) }\end{array}$ & Polyethylene glycol & High polarity & 60 & 0.25 & 0.25 & 7,13 \\
\hline $\begin{array}{l}\text { SE54 } \\
(J \& W)\end{array}$ & (5\%Phenyl)(1\%Vinyl)-methylpolysiloxane & Low polar & 60 & 0.32 & 1 & 11 \\
\hline $\begin{array}{l}\text { Rxiß-5ms } \\
\text { (Restek) }\end{array}$ & (5\%-Phenyl)-methylpolysiloxane & Low polar & 30 & 0.25 & 1.00 & 2,17 \\
\hline $\begin{array}{l}\text { Supelcowax }{ }^{m}-10 \\
\text { (Supelco) }\end{array}$ & CARBOWAX® 20M poly(ethylene glycol) & High polarity & 60 & 0.25 & 0.25 & $4,6,14$ \\
\hline
\end{tabular}

In references: 1: Sabio et al., 1998; 2: Ramírez and Cava, 2007; 3: Carrapiso et al., 2002; 4: Narváez-Rivas et al., 2010; 5: Timón et al., 2002; 6: Narváez-Rivas et al., 2011; 7: Sánchez-Peña et al., 2005; 8: Andrés et al., 2007; 9: López et al., $1992 ; 10$ = Timón et al., 1998; 11: García et al., 1991; 12: Jurado et al., 2009; 13: García-González et al., 2008; 14: Narváez-Rivas et al., 2010; 15: Timón et al., 2001; 16: Ruiz et al., 1999; 17: Ruiz et al., 1998a; 18: Ruiz et al., 2001; 19: Andrés et al., 2002; 20: Andrade et al., 2009; 21: Aparicio-Ruiz and Morales, 1998; 22: García-González et al., 2006. 
columns was 5\%-Phenyl-methylpolysiloxane, except in SE54 (J\&W), in which it was (5\%Phenyl, $1 \%$ Vinylmethylpolysiloxane. On the other hand, the stationary phases used in high polar columns were polyethylene glycol and nitroterephthalic acid modified polyethylene glycol. As shown in this table, the most commonly used column has been the HP-5 $(50 \mathrm{~m} \times 0.32 \mathrm{~mm}, 1.05 \mu \mathrm{m})$, although Carrapiso et al. (2002) made a comparison between this low polar column and a high polar column (HP-FFAP, $30 \mathrm{~m} \times 0.32 \mathrm{~mm}, 0.25 \mu \mathrm{m}$ ), finding that coelutions of some compounds exist using this first one and concluding that the use of the second column is advisable to avoid wrong assignments of odor descriptions to abundant compounds with clear mass spectra that may co-elute with others. This coelution also existed in other columns of low polarity auch as the Rxi®-5ms (Restek) (Ruiz et al., 1998). However, there are different studies on the same type of sample (subcutaneous fat) carried out by several authors (Timón et al., 2002; Narváez-Rivas et al., 2010a) using two columns (high and low polarity, respectively) and the amount of volatile compound identified was totally different (105 and 52 compounds, respectively).This can be due to the temperature used in the isolation (45 and $40^{\circ} \mathrm{C}$, respectively) rather than the use of different columns. Therefore, the use of columns with different polarity and dimensions can have an influence on the resolution of some peaks but not in the number of them, which is influenced by the different techniques of isolation used previously and the conditions employed.

Nitrogen (Timón et al., 2002; Narváez-Rivas et al., 2010a), hydrogen (Narváez-Rivas et al., 2010b; Sánchez-Peña et al., 2005; García-González et al., 2008, Narváez-Rivas et al., 2010a) or helium (Sabio et al., 1998; Ramírez and Cava, 2007; López et al., 1992; Timón et al., 1998; Andrade et al., 2009) have been used as carrier gas. As can be observed, helium is the most commonly used carrier gas, but according to the van Deemter equation, hydrogen is better since the chromatographic column has better efficiency when the molecular weight of the carrier gas is lower (van Deemter et al., 1956). Several oven temperature programs have been employed, starting at $30^{\circ} \mathrm{C}$ (López et al., 1992), $35^{\circ} \mathrm{C}$ (Sabio et al., 1998; Carrapiso et al., 2002; Timón et al., 2002; Timón et al., 1998; Timón et al., 2001) or $40^{\circ} \mathrm{C}$ (Ramírez and Cava, 2007; Narváez-Rivas et al., 2010b; Sánchez-Peña et al., 2005; Andrés et al., 2007; García et al., 1991; Jurado et al., 2009; GarcíaGonzález et al., 2008, Narváez-Rivas et al., 2010a; Ruiz et al., 2001; Andrés et al., 2002; Andrade et al., 2009) and increasing up to $175^{\circ} \mathrm{C}$ (Sabio et al., 1998), $180^{\circ} \mathrm{C}$ (López et al., 1992), $200^{\circ} \mathrm{C}$ (SánchezPeña et al., 2005; Andrés et al., 2007; GarcíaGonzález et al., 2008; 28), $220^{\circ} \mathrm{C}$ (Narváez-Rivas et al., 2010a, 2010b), $230^{\circ} \mathrm{C}$ (Timón et al., 1998), $240^{\circ} \mathrm{C}$ (García et al., 1991) or $250^{\circ} \mathrm{C}$ (Ramírez and Cava, 2007; Carrapiso et al., 2002; Timón et al., 2002; Jurado et al., 2009; Timón et al., 2001; Ruiz et al., 2001; Andrade et al., 2009). Splitless mode injection is the most widely used by authors who study the volatile compounds of Iberian ham, but the split injection mode has also been used although only by Narváez-Rivas et al. (2010a, 2010b). In accordance with a study made by Schomburg et al. (1983), high precision and accuracy of relative and absolute peak areas can be achieved with both the cold splitless and the cold on-column modes, and with the cold split mode technique the performance of quantitative analyses is also improved but a certain discrimination by volatility and a slightly increased standard deviation for the peak area data still cannot be avoided. However, split injection is required when a cold trap is not used between the desorption system and chromatographic column (Narváez-Rivas et al., 2010a, 2010b).

\subsection{High-performance liquid chromatography (HPLC)}

The volatile aldehydes from hams were studied during the ripening process by Antequera et al. (1992) using HPLC according to the method of Reindl and Stan (1982). These aldehydes produced during processing were converted into 2,4-dinitrophenylhydrazone $(2,4-\mathrm{DNP})$ derivatives prior to mixing the meat $(5-10 \mathrm{~g})$ with cold ethanol. After centrifugation under refrigeration $\left(0^{\circ} \mathrm{C}\right)$, the supernatant was distilled under vacuum $(2.5-4 \mathrm{kPa})$ and this distillate was filled with a 2,4-DNP solution and mixed with $n$-hexane; the solvent was then removed using a rotary evaporator. The dry 2,4-DNP derivatives were dissolved in methanol and separated using reversedphase HPLC (Supelcosil LC 18 column, $4.6 \mathrm{~mm} \times 250$ $\mathrm{mm}, 5 \mu \mathrm{m}$ ) with an isocratic elution of $1 \mathrm{ml} / \mathrm{min}$. The eluent was acetonitrile:water:tetrahydrofuran (75:24:1) and the temperature in the column was $40^{\circ} \mathrm{C}$. A UVVis detector was used and the detection took place at $360 \mathrm{~nm}$. The aldehydes identified during the maturation of Iberian hams were hexanal, heptanal, octanal, nonanal, 2-nonenal, 2,4-nonadienal and 2,4-decadienal, with the most abundant being hexanal and nonanal.

The use of this technique is not the most adequate since GC with any sample preparation technique is an easier method of analysis for these analytes. Thus, all of the cited aldehydes can be analyzed in an easy and rapid way by GC.

\subsection{Identification and quantification}

The compounds can be identified (i) by comparison with commercial reference compounds (NarváezRivas et al., 2010b; Sánchez-Peña et al., 2005; López et al., 1992; Narváez-Rivas et al., 2010a), (ii) by comparison of Kovats indices (Sabio et al., 1998; Ramírez and Cava, 2007; Carrapiso et al., 2002; Timón et al., 2002; Andrés et al., 2007; García et al., 1991; Jurado et al., 2009; Timón et al., 2001; Ruiz et al., 2001; Andrés et al., 2002; Merkle and Larick, 1994; Andrade et al., 2009) with those described by other authors (Kondjoyan and Berdagué, 1996; Kerscher and Grosch, 1997; Rychlik et al., 1998; Reiners and Grosch, 1998; Kovats, 1965; Berdagué et al., 1991; Berdagué et al., 1993; Buscailhon et al., 
1993; Hinrichsen and Pedersen, 1995; Acree and Arn, 1997) and on the web at http://webbook.nist.gov/ (Ramírez and Cava, 2007), and (iii) by comparison of their mass spectra with those contained in libraries, such as NBS (National Bureau of Standards) (López et al., 1992), Wiley (Ramírez and Cava, 2007; Carrapiso et al., 2002; Narváez-Rivas et al., 2010b; Andrés et al., 2007; Timón et al., 1998; Jurado et al., 2009; Narváez-Rivas et al., 2010a; Timón et al., 2001; Ruiz et al., 2001; Andrés et al., 2002), NIST/EPA/NIH (Carrapiso et al., 2002; Narváez-Rivas et al., 2010b; Timón et al., 2002; Andrés et al., 2007; Timón et al., 1998; Jurado et al., 2009; Narváez-Rivas et al., 2010a; Timón et al., 2001; Ruiz et al., 2001; Andrés et al., 2002; Andrade et al., 2009) and MassLab v.1.3. (Sánchez-Peña et al., 2005).

The mass spectra have been obtained by electronic impact at $70 \mathrm{eV}$, with a multiplier voltage of 1756 V (Timón et al., 2002; Andrés et al., 2007; Timón et al., 1998; Timón et al., 2001; Ruiz et al., 2001; Andrés et al., 2002), 1675 V (Carrapiso et al., 2002) or 1650 V (Ramírez and Cava, 2007; Andrade et al., 2009) and a collected data rate of 1 scan s-1 over the $\mathrm{m} / \mathrm{z}$ range of 30 to 500 . The transfer line to the MS is held at high temperatures at $150^{\circ} \mathrm{C}$ (Narváez-Rivas et al., 2010a, 2010b), $200^{\circ} \mathrm{C}$ (Timón et al., 2001), $210^{\circ} \mathrm{C}$ (Carrapiso et al., 2002) or $280^{\circ} \mathrm{C}$ (Timón et al., 2002).

The quantification of volatiles can be done with a mass selective detector (MS) or a flame ionization detector (FID) (Sánchez-Peña et al., 2005), using an internal or external (Sánchez-Peña et al., 2005) standard and calculating the different response factors for each compound with respect to the standard. The peak area of the analyte is used as an analytical signal. In addition, the quantification of individual volatile compounds has been carried out by evaluating the corresponding relative percentages according to the area normalization method (NarváezRivas et al., 2010a, 2010b; García et al., 1991; Ruiz et al., 2001).

GC-sniffing/olfactometry has been employed to determine the odor and the sensory characterization of volatile compounds. In table 2 , the sensory attributes

Table 2

Odor-active volatile compounds of dry-cured Iberian hams and their sensory attributes

\begin{tabular}{|c|c|c|}
\hline Volatile compound & Sensory atribute & Reference \\
\hline Hexane & $\begin{array}{l}\text { Spicy } \\
\text { Alkane }\end{array}$ & $\begin{array}{l}3 \\
2\end{array}$ \\
\hline Heptane & $\begin{array}{l}\text { Alkane } \\
\text { Sweet }\end{array}$ & $\begin{array}{l}3,2 \\
3\end{array}$ \\
\hline Octane & $\begin{array}{l}\text { Alkane } \\
\text { Sweet }\end{array}$ & $\begin{array}{l}2,3 \\
3\end{array}$ \\
\hline Methyl benzene & $\begin{array}{l}\text { Strong } \\
\text { Plastic, glue }\end{array}$ & $\begin{array}{l}2,3 \\
3\end{array}$ \\
\hline Ethyl benzene & Dry, glue, unpleasant & $\begin{array}{l}2 \\
3\end{array}$ \\
\hline 2-Propanone & $\begin{array}{l}\text { Fruity, apple, pear } \\
\text { F }\end{array}$ & $\begin{array}{l}2 \\
3\end{array}$ \\
\hline 2-Butanone & Ethereal & 2,3 \\
\hline 2,3-Butanodione & $\begin{array}{l}\text { Buttery } \\
\text { Vanilla/caramel-like } \\
\text { Sweet }\end{array}$ & $\begin{array}{l}2,3,4 \\
1,3 \\
1,4\end{array}$ \\
\hline 2-Pentanone+3-pentanone & $\begin{array}{l}\text { Sweet } \\
\text { Fruity, green } \\
\text { Tropical fruit }\end{array}$ & $\begin{array}{l}3 \\
1,3,4 \\
1,4\end{array}$ \\
\hline 1-Penten-3-one & Rotten, sewer-like, fruity & 1 \\
\hline 3-Mercapto-2-pentanone & $\begin{array}{l}\text { Cured ham, toasted } \\
\text { Fruity, sewage-like, fatty }\end{array}$ & $\begin{array}{l}1 \\
1,4\end{array}$ \\
\hline 2-Heptanone & $\begin{array}{l}\text { Spicy, blue cheese } \\
\text { Acorn } \\
\text { Nutty, dry-cured ham-like, toasted }\end{array}$ & $\begin{array}{l}2,3 \\
3 \\
4\end{array}$ \\
\hline 2-Octanone & Fruity, green, floral, fresh & 3 \\
\hline Octen-2-one & Green herbaceous & 1 \\
\hline Octen-3-one & $\begin{array}{l}\text { Spicy, } \\
\text { Mushroom, dirty } \\
\text { Rust-like } \\
\text { Dust }\end{array}$ & $\begin{array}{l}3 \\
1,3,4,5 \\
4 \\
1\end{array}$ \\
\hline
\end{tabular}




\begin{tabular}{|c|c|c|}
\hline Volatile compound & Sensory atribute & Reference \\
\hline 2-Nonanone & $\begin{array}{l}\text { Floral, fruity } \\
\text { Blue cheese }\end{array}$ & $\begin{array}{l}3 \\
2,3\end{array}$ \\
\hline Propanal & Almond-like, green & 4 \\
\hline 2-Methyl propanal & $\begin{array}{l}\text { Toasted } \\
\text { Fruity } \\
\text { Pungent } \\
\text { Alcoholic } \\
\text { Nutty }\end{array}$ & $\begin{array}{l}1,4,5 \\
1 \\
1,4 \\
5 \\
4\end{array}$ \\
\hline 2-Methylbutanal & $\begin{array}{l}\text { Rancid, almond-like, toasted } \\
\text { Fruity }\end{array}$ & $\begin{array}{l}1,5 \\
5\end{array}$ \\
\hline 3-Methylbutanal & $\begin{array}{l}\text { Acorn } \\
\text { Nutty } \\
\text { Almond, toasted } \\
\text { Cheesy, salty } \\
\text { Fruity } \\
\text { Pungent } \\
\text { Malty }\end{array}$ & $\begin{array}{l}3 \\
2,5 \\
1 \\
2,3 \\
1,3 \\
5 \\
4\end{array}$ \\
\hline Pentanal & $\begin{array}{l}\text { Nutty, toasted } \\
\text { Fruity }\end{array}$ & $\begin{array}{l}1,2,4 \\
1,2\end{array}$ \\
\hline Hexanal & $\begin{array}{l}\text { Rancid } \\
\text { Fatty } \\
\text { Fruity } \\
\text { Acorn } \\
\text { Green } \\
\text { Grassy }\end{array}$ & $\begin{array}{l}2 \\
3 \\
1,5 \\
1,4 \\
1,2,3,4 \\
2,3,5\end{array}$ \\
\hline Heptanal & $\begin{array}{l}\text { Oily } \\
\text { Toasted } \\
\text { Fruity } \\
\text { Sewage } \\
\text { Cured ham-like } \\
\text { Fatty }\end{array}$ & $\begin{array}{l}2,3 \\
1,2 \\
1,2,4 \\
1,4 \\
1,2,3 \\
1,2,3,4\end{array}$ \\
\hline 2-hexenal & $\begin{array}{l}\text { Fruity, strawberry } \\
\text { Olive oil-like } \\
\text { Apple-like }\end{array}$ & $\begin{array}{l}1,4 \\
4 \\
1\end{array}$ \\
\hline 3-hexenal & $\begin{array}{l}\text { Green, acorn-like } \\
\text { Fruity }\end{array}$ & $\begin{array}{l}1,4 \\
1\end{array}$ \\
\hline 2-Heptenal & $\begin{array}{l}\text { Green, fatty, } \\
\text { Fried food-like } \\
\text { Fruity, almond }\end{array}$ & $\begin{array}{l}3 \\
1 \\
1,3\end{array}$ \\
\hline Octanal & $\begin{array}{l}\text { Green, fresh } \\
\text { Meat } \\
\text { Stew-like, boiled meat-like, rancid } \\
\text { Grass, fruity } \\
\text { Rancid, sewage, roasted }\end{array}$ & $\begin{array}{l}2,3 \\
3 \\
1 \\
5 \\
4\end{array}$ \\
\hline 2-octenal & $\begin{array}{l}\text { Leaves, pungent, fatty } \\
\text { Rancid } \\
\text { Tropical fruit-like } \\
\text { Fruity }\end{array}$ & $\begin{array}{l}3 \\
1 \\
1,4 \\
1,3,4\end{array}$ \\
\hline Nonanal & Rancid, fatty & 2,3 \\
\hline 2-Nonenal & Fatty, waxy & 3 \\
\hline Decanal & $\begin{array}{l}\text { Penetrating, Sweet, floral } \\
\text { Citrus, waxy }\end{array}$ & $\begin{array}{l}2 \\
2,3\end{array}$ \\
\hline 2,4-Decadienal & Fatty, rancid & 3 \\
\hline Benzaldehído & $\begin{array}{l}\text { Almond } \\
\text { Bitter almond, penetrating }\end{array}$ & $\begin{array}{l}2 \\
3\end{array}$ \\
\hline
\end{tabular}




\begin{tabular}{|c|c|c|}
\hline Volatile compound & Sensory atribute & Reference \\
\hline Phenylacetaldehyde & Flower, solvent-like, fruity & 5 \\
\hline Etanol & $\begin{array}{l}\text { Alcohol } \\
\text { Sweet }\end{array}$ & $\begin{array}{l}3 \\
2,3\end{array}$ \\
\hline 2-Propanol & $\begin{array}{l}\text { Buttery taste } \\
\text { Alcohol, dry }\end{array}$ & $\begin{array}{l}2,3 \\
3\end{array}$ \\
\hline 2-Methyl propanol & Wine, penetrating & 3 \\
\hline Butanol & $\begin{array}{l}\text { Medicinal } \\
\text { Fruity }\end{array}$ & $\begin{array}{l}2,3 \\
3\end{array}$ \\
\hline 2-Butanol & Wine & 3 \\
\hline 3-Methyl butanol & $\begin{array}{l}\text { Green } \\
\text { Wood, acorn, pleasant green }\end{array}$ & $\begin{array}{l}2 \\
3\end{array}$ \\
\hline 2-Methyl-3-buten-2-ol & Earthy & 3 \\
\hline Pentanol & $\begin{array}{l}\text { Pungent } \\
\text { Strong, balsamic } \\
\text { Somewhat sweet }\end{array}$ & $\begin{array}{l}3 \\
2,3 \\
2\end{array}$ \\
\hline Hexanol & Fruity, green & 2,3 \\
\hline 2-Heptanol & Oily, sweet & 3 \\
\hline 1-Octen-3-ol & $\begin{array}{l}\text { Mushroom } \\
\text { Earthy } \\
\text { Dust } \\
\text { Rust-like }\end{array}$ & $\begin{array}{l}2,3,4 \\
1 \\
1,3 \\
4\end{array}$ \\
\hline Octanol & $\begin{array}{l}\text { Fatty } \\
\text { Strong } \\
\text { Acid }\end{array}$ & $\begin{array}{l}2 \\
3 \\
3,2\end{array}$ \\
\hline Nonanol & Fatty, green & 3 \\
\hline Limonene & $\begin{array}{l}\text { Lemon, wood } \\
\text { Citric, fresh }\end{array}$ & $\begin{array}{l}2 \\
3\end{array}$ \\
\hline$\alpha$-Pinene & Sharp, pine & 3 \\
\hline 2-Ethyl furane & Sweet & 3 \\
\hline 2-Penthyl furane & Green fruity & 3 \\
\hline Butyl acetate & Fruit & 3 \\
\hline Acetic acid & Sweat, acid & 5 \\
\hline Propanoic acid & Sweat, acid, foot-like & 5 \\
\hline Butanoic acid & $\begin{array}{l}\text { Fatty } \\
\text { Rancid } \\
\text { Cheesy }\end{array}$ & $\begin{array}{l}2 \\
3 \\
3,2\end{array}$ \\
\hline 2-Methyl propanoic acid & Iron, fishy & 3 \\
\hline 3-Methyl butanoic acid & Foot-like, acid, spoiled ham & 5 \\
\hline Pentanoic acid & Meaty, roasted, spoiled ham & 5 \\
\hline Hexanoic acid & Fatty, cheesy, sweat & 2 \\
\hline 2-Methyl-3-furanothiol & Cured ham, toasted, nutty & 1,4 \\
\hline Methanethiol & Rotten eggs, meat or fish, cheesy & 1,5 \\
\hline 2-Furfurylthiol & Rotten eggs, meat or fish, cheesy & 1 \\
\hline Methional & $\begin{array}{l}\text { Boiled meat, cured ham, } \\
\text { Potato-like } \\
\text { Stew-like }\end{array}$ & $\begin{array}{l}1 \\
1,5 \\
5\end{array}$ \\
\hline Hydrogen sulfide & Boiled or rotten eggs, sewage & 1 \\
\hline Dimethyl disulfide & $\begin{array}{l}\text { Cauliflowers, vegetables } \\
\text { Rotten, spoiled ham, burnt }\end{array}$ & $\begin{array}{l}3 \\
5\end{array}$ \\
\hline
\end{tabular}




\begin{tabular}{lll}
\hline \multicolumn{1}{c}{ Volatile compound } & \multicolumn{1}{c}{ Sensory atribute } & Reference \\
\hline \multirow{2}{*}{ Dimethyl trisulfide } & Rotten egg & 1,5 \\
& Burnt & 1 \\
& Sewage-like & 5 \\
2-Acetyl-1-pyrroline & Overheated meat-like, cured ham & 1 \\
& Roasted & 1,4 \\
& Nutty, popcorn & 5 \\
2-Propionyl-1-pyrroline & Toasted & 4,5 \\
& Stew-like, boiled meat & 1 \\
Ethyl butanoate & Rancid & 1,4 \\
& Sewage, roasted & 4 \\
Ethyl 2-methylpropanoate & Fruity & 5 \\
& Fruity & $1,4,5$ \\
& Toasted & 1,4 \\
Ethyl 2-methylbutirate & Pungent & 1 \\
& Strawberry-like & 5 \\
& Fruity & $1,5,4$ \\
\end{tabular}

In references: 1: Carrapiso et al., 2002; 2: Sánchez-Peña et al., 2005; 3: García-González et al., 2008;

4: Carrapiso and García, 2004; 5: Carrapiso et al., 2010.

of volatiles from dry-cured Iberian ham are shown, including aldehydes, ketones and alcohols as the most abundant odor-active volatile compounds in this kind of product.

The method employed for the assignment of the odor potencies of the volatile compounds is as follow: during GC-olfatometry, assessors (experienced in sensory analysis and trained in GC-olfatometry) are asked to give a description of each perceived odor, its length and intensity, to aid in odorant identification (Carrapiso et al., 2002; García-González et al., 2008, Carrapiso and García, 2004; Carrapiso et al., 2010).

According to Aparicio-Ruiz and Morales (1998), only a small percentage of volatiles are odor-active and their sensory characteristics can change with their concentration and possible synergy with other compounds from the matrix. The chemical knowledge of these attributes may help to establish the basis for a harmonized procedure of a sensory assessment of dry-cured hams (García-González et al., 2006).

Carrapiso et al. (2002) found that 28 volatiles are the most odor-active compounds in Iberian ham, including 11 aldehydes, 7 sulfur-containing compounds, 5 ketones, 2 nitrogen-containing compounds, 2 esters and an alcohol (see Table 2). Among them, the highest odor potencies were found for 2-methyl-3-furanthiol, 2-heptanone, 3-methylbutanal, methanethiol, hexanal, hydrogen sulfide, 1-penten-3-one, 2-methylpropanal, ethyl 2-methylbutyrate, and (E)-2-hexenal. Furthermore, they found that none of the numerous or abundant hydrocarbons (neither aliphatic nor aromatic hydrocarbons) reported in previous studies performed on dry-cured hams were potent odorants. It would be stood out that the presence of 2-propionyl-1-pyrroline in foodstuffs as an odorant seems to be infrequent, but this could due to its co-elution with octanal.
García-González et al. (2008) studied the relationship between 45 volatile compounds and 17 sensory attributes of dry-cured Iberian hams (see table 2). They determined the odor thresholds of the volatile compounds and their sensory characterization by dilution analysis. Six sensory attributes (acorn odor and flavor, rancid odor, rancid taste, fat rancid and fat pungent flavors) were explained by regression equations (adjusted $-R^{2} \geqslant 0.70$ ) based on ten compounds: benzaldehyde, 2-heptanone, hexanal, hexanol, limonene, 3-methylbutanal, 3-methylbutanol, 2-nonanone, octanol, pentanol. Moreover, they found that the most noteworthy volatile compounds, in terms of basic contribution to the ham flavor matrix, are the following: Hexanal, 3-methylbutanal, limonene, hexanol, octanol and E-2-nonenal. The first two are in agreement with authors mentioned above (Carrapiso et al., 2002).

In the study carried out by Sánchez-Peña et al. (2005), the hams produced in Spain and France could be distinguished by 4 odor-active volatile compounds from semitendinosus muscle (2-butanone and 2-octanone) and the subcutaneous fat (methyl benzene and octanol). On the other hand, the volatile composition was influenced by the breed type (Iberian and White). Iberian hams were clearly characterized by the information from two volatile compounds: Octanol (from subcutaneous fat) and 3-methyl-1butanol (from bicep femoris).

In 2004, the odorants from the inter-muscular fat of Iberian ham were characterized and compared with those of lean meat samples (Carrapiso and García, 2004). Sulfur-containing compounds (specifically hydrogen sulphide, methanethiol and 2-methyl-3furanthiol) were clearly involved in the typical odor of lean meat samples but not in the inter-muscular 
fat odor, and were probably the main compounds responsible for odor differences. However, certain aldehydes (propanal, 2-hexenal, 2-octenal), ketones (1-octen-3-one, 2-pentanone, 2,3-butanedione, 2-heptanone) and esters (ethyl 2-methylpropanoate, ethyl 2-methylbutanoate), as well as some unknown compounds, contributed to the overall observed differences. Propanal and 2,3-butanedione were found as odorants of inter-muscular fat but not of lean meat samples.

Carrapiso et al. (2010). made a study in which they characterized the most odor-active compounds of markedly bone tainted Iberian hams and compared them with those of unspoiled hams, finding that those with a putrid, strawberry-like odor or a putrid, yeastlike odor were compounds usually found in the unspoiled product and in other dry-cured hams, most being odorants of Iberian ham. Ethyl-2-methyl propanoate, phenylacetaldehyde and acetic, butanoic, 3-methylbutanoic and pentanoic acids were only found in the spoiled samples. In addition, they found several new odor-active compounds in Iberian ham, such as ethyl butanoate, phenylacetaldehyde and acetic, propanoic, 3-methyl-butanoic and pentanoic acids, all of which appeared only in the spoiled samples, with the exception of the first one.

As well as the factor related to the initial characteristics of the raw material, from an analytical point of view, the differences in composition of volatile compounds could be probably due to the isolation and enrichment method and of course to the sampling because it is important to note that ham is a solid, heterogeneous material and in this case, the differences in sampling contribute largely to the final results.

Other techniques that would be adequate in this kind of sample, such as two-dimensional GC, have not been employed in any case to a better purification and separation of volatile compounds.

\section{VOLATILE COMPOUNDS}

In Iberian dry-cured hams, a total of 411 volatile compounds have been identified using the different techniques explained above. These compounds were grouped into aldehydes, alcohols, ketones, esters and ethers, nitrogenous compounds, n-alkanes, aromatic and cyclic hydrocarbons, sulphur compounds, terpenes, lactones, carboxylic acids, chloride compounds and amides. They have been listed in several Tables (1.4-1.8) for better comprehension. Differences in results of the different authors are related to the various extraction techniques applied, and to other factors related to raw material (such as different feedings, anatomical locations, pig genotypes) or ripening conditions.

There are some studies which conclude that the amount of volatile compounds is higher in hams from pigs fed on "Montanera" than in hams from pigs fed on concentrate feeds ("Cebo") (Timón et al., 2002; López et al., 1992). The particular fatty acid composition of subcutaneous fat of "Montanera" hams causes these differences, since lipid oxidation gives rise to volatile compounds (García et al., 1991). However, despite the fact that the fatty acid profiles of hams from pigs fed on concentrate feeds and those from pigs fed on concentrate feeds but with $\alpha$-tocopherol supplementation, the volatile content of the second group is situated between "Montanera" and "Cebo" hams (Timón et al., 2002). Therefore, these differences would be caused by $\alpha$-tocopherol supplementation and antioxidant presence ("Montanera" and $\alpha$-tocopherol supplementation) and could contribute to a high intensity and quality of aroma of hams (Timón et al., 2002; Cava et al., 1999). No significant differences have been found due to the sex of the animal (Ramírez and Cava, 2007).

Some authors have demonstrated that there are important differences among different types of drycured hams depending on the type of raw material and the technology used and that hams with longer processing times are richer in volatile compounds (Iberian and Corsican) (Sabio et al., 1998).

\subsection{Hydrocarbons}

This group is numerous, a total of $62 \mathrm{n}$-alkanes have been detected (Table 3). However, only 18 of them have been identified by several authors (Sabio et al., 1998;

Table 3

Volatile hydrocarbons previously reported in dry-cured Iberian ham

\begin{tabular}{|c|c|}
\hline Aliphatic hydrocarbons & Nonadecane $^{10}$ \\
\hline 2-Methyl-2-butene ${ }^{3,13}$ & Heneicosane $e^{10}$ \\
\hline Pentane ${ }^{10,17,18}$ & Docosane $^{10}$ \\
\hline 2-Methylpentane $e^{2,4,14,19}$ & Myrcene $^{8}$ \\
\hline 3-Methylpentane $e^{2,19}$ & Aromatic and cyclic hydrocarbons \\
\hline 3-Ethylpentane ${ }^{19}$ & Methyl cyclopentane $e^{1,15,16,18}$ \\
\hline 4,4-Dimethyl-2-pentene ${ }^{19}$ & Butyl cyclopentane $e^{3,13}$ \\
\hline 1,3-Pentadiene ${ }^{17}$ & Ethyl cyclopentane ${ }^{15}$ \\
\hline Hexane $e^{1,4,6,9,12,14,17-19}$ & 1,2,3,4-Tetramethyl-cyclopentane $e^{3,13}$ \\
\hline 3-Methylhexane $3,13,15,19$ & 1,2-Diethyl-cyclobutane $e^{3,13}$ \\
\hline
\end{tabular}




\begin{tabular}{|c|c|}
\hline 2,2,5-Trimethyl-hexane $e^{3,13}$ & Benzene $^{15}$ \\
\hline 2,2,5,5-Tetramethyl-hexane $e^{3,13}$ & Cycloalkene $^{16}$ \\
\hline Heptane $e^{1,2,4,6,9,11,12,15,17-19}$ & Methylbenzene (toluene) ${ }^{1,3,4,5,6,9,12-18}$ \\
\hline Methylene heptane ${ }^{4}$ & 1-Methylethylbenzene $e^{17}$ \\
\hline 3-Methylheptane ${ }^{14,15}$ & Ethyl benzene $e^{1,6,8,12,14,18}$ \\
\hline 2,4-Dimethyl-heptane $e^{3,5,13}$ & Ethenylbenzene $e^{4,15}$ \\
\hline 2,4,6-Trimethyl-heptane $e^{3,13}$ & Propylbenzene $e^{3,9,13,15,17}$ \\
\hline 2,2,4,6,6-Pentamethyl-heptane ${ }^{5}$ & Pentylbenzene $^{18}$ \\
\hline Octane $e^{1,4,6,9,11,12,15,16}$ & 2,4-Diphenyl-4-methyl-2(Z)pentene ${ }^{16}$ \\
\hline 2,2,4,4-Tetramethyl-octane ${ }^{5}$ & 1,2-Dimethylbenzene (o-xylene) ) $^{1,3,5,8,13,15}$ \\
\hline 1 -Octene ${ }^{17,18}$ & $\begin{array}{l}\text { 1,3-Dimethylbenzene }(\mathrm{m}- \\
\text { xylene })^{1-5,13,14-16,18}\end{array}$ \\
\hline $4-O c t e n e^{15}$ & 1,4-Dimethylbenzene $(p \text {-xylene })^{3-5,8,13-16,18}$ \\
\hline 2-Octene $e^{3,4,13-15,17}$ & Diethyl benzene $^{1}$ \\
\hline $1,3-$ Octadiene ${ }^{15}$ & Ethyl toluene ${ }^{1}$ \\
\hline $1,3,6-$ Octatriene ${ }^{16}$ & Trimethyl benzene ${ }^{1}$ \\
\hline Nonane $^{3,4,9,8,13-15,18}$ & 1,2,2-Trimethyl benzene ${ }^{1}$ \\
\hline 2,6-Dimethyl-nonane ${ }^{2}$ & 1,2,3-Trimethyl benzene $e^{3,8,13}$ \\
\hline 2,2,3-Trimethyl-nonane ${ }^{3,13}$ & 1,2,4-Trimethyl benzene $e^{3,13,15}$ \\
\hline 5-(1-Methyl-propyl)-nonane $e^{3,13}$ & 1,3,5-Trimethyl benzene $e^{3,5,13,15}$ \\
\hline Decane $^{2,4,9,10,14-16,18}$ & 1-Ethyl-2-methylbenzene ${ }^{15}$ \\
\hline 2-Methyldecane ${ }^{9}$ & 1-Ethyl-4-methylbenzene ${ }^{3,4,13-15}$ \\
\hline 5-Methyldecane ${ }^{9}$ & 5-Methyldodecane ${ }^{9}$ \\
\hline 2,6,7-Trimethyl-decane ${ }^{5}$ & 2-Ethyl-1-dodecene ${ }^{9}$ \\
\hline 2,3,5,8-Tetramethyl-decane $e^{3,13}$ & 1-Methyl-3-(1-methyl-ethyl)-benzene ${ }^{3,13}$ \\
\hline 4-Methyl-1-decene $e^{3,13}$ & 1,3-Dimethyl-3ethyl-benzene ${ }^{8}$ \\
\hline Undecane $e^{1,9,10,18}$ & 3-Ethyl-1,2-dimethylbenzene ${ }^{8}$ \\
\hline 3-Methyl-5-undecene $e^{3,13}$ & 4-Ethyl-1,2-dimethylbenzene $e^{3,9,13}$ \\
\hline 4-Methyl-1-undecene $e^{3,13}$ & 3-Ethylfurane ${ }^{12}$ \\
\hline Methylundecane ${ }^{10}$ & 2-Butylfurane $e^{13}$ \\
\hline 2,6-Dimethylundecane $e^{2,3,5,13}$ & $1,3,4,5$-Tetramethylbenzene ${ }^{9}$ \\
\hline Dodecane $e^{1,3,9,10,13,14,18}$ & 1-Ethyl-1-methyl-cyclohexane $e^{3,13}$ \\
\hline 1-Dodecene ${ }^{9}$ & 1-1'-Biphenyl ${ }^{19}$ \\
\hline 2-Dodecene ${ }^{9}$ & 1,4-bis(1,1-dimethylethyl)benzene ${ }^{19}$ \\
\hline 3-Dodecene ${ }^{9}$ & Methylcyclohexane ${ }^{19}$ \\
\hline Methyldodecane ${ }^{10}$ & 2-Ethenylcyclohexane $e^{3,4,13,14}$ \\
\hline 4-Methyldodecane ${ }^{2}$ & Propylcyclohexane $^{15}$ \\
\hline Cyclododecane $^{9}$ & Octyl-cyclohexane $e^{3,13}$ \\
\hline Tridecane $^{10,17,18}$ & Tetramethyl benzene $e^{3,13}$ \\
\hline 6-Methyl-tridecane ${ }^{5}$ & Heptylbenzene $3,13,17$ \\
\hline 1-Ethyl-3,5-dimethylbenzene ${ }^{9}$ & Nonylbenzene ${ }^{17,18}$ \\
\hline 2-Ethyl-1,3-dimethyl-benzene ${ }^{3,13}$ & 2-Ethylfurane $\mathrm{e}^{13,15}$ \\
\hline Tetradecane $e^{9,10,14,17,18}$ & 2-Pentylfurane ${ }^{7,11-13,16-18}$ \\
\hline 1-Tetradecene ${ }^{9}$ & 2,3-Dihydrofurane ${ }^{13}$ \\
\hline 2-Tetradecene ${ }^{9}$ & 4-Propyl-2-methylfurane ${ }^{15}$ \\
\hline
\end{tabular}




\begin{tabular}{|c|c|}
\hline 3-Tetradecene ${ }^{9}$ & 2-Methyl-4,5-dihydrofurane ${ }^{8}$ \\
\hline Pentadecane ${ }^{9,10,17,18}$ & 2,2,4-Trimethyl-2,5-dihydrofurane ${ }^{8}$ \\
\hline 5-Methyl-pentadecane $e^{3,13}$ & 2,5-Dimethyltetrahydrofurane ${ }^{8}$ \\
\hline Hexadecane $e^{9,10,18}$ & Naphthalene $e^{9,3}$ \\
\hline 1-Hexadecene ${ }^{9}$ & Decahydro-naphthalene $e^{3,13}$ \\
\hline 3-Hexadecene ${ }^{9}$ & 2-Methyl-decahydronaphthalene ${ }^{3,13}$ \\
\hline Heptadecane $e^{9,10,18}$ & Germacrane $\mathrm{B}^{3,13}$ \\
\hline Octadecane $e^{9,10}$ & Styrene $e^{8,17-19}$ \\
\hline 1-Octadecene ${ }^{9}$ & \\
\hline
\end{tabular}

In references: 1: Sabio et al., 1998; 2: Ramírez and Cava, 2007; 3: Narváez-Rivas et al., 2010b; 4: Timón et al., 2002; 5: Narváez-Rivas et al., 2011; 6: Sánchez-Peña et al., 2005; 7: Andrés et al., 2007; 8: López et al., 1992; 9: Timón et al., 1998; 10: García et al., 1991; 11: Jurado et al., 2009; 12: García-González et al., 2008; 13: Narváez-Rivas et al., 2010a; 14: Timón et al., 2001; 15: Ruiz et al., 1999; 16: Ruiz et al., 1998a; 17: Ruiz et al., 2001; 18: Andrés et al., 2002; 19: Andrade et al., 2009.

Ramírez and Cava, 2007; Narváez-Rivas et al., 2010a, 2010b; Timón et al., 2002; Sánchez-Peña et al., 2005; López et al., 1992; Timón et al., 1998; García et al., 1991; Jurado et al., 2009; García-González et al., 2008; Timón et al., 2001; Ruiz et al., 1999; Ruiz et al., 2001; Andrés et al., 2002; Andrade et al., 2009). They are pentane, 3-methyl pentane, 2-methyl pentane, hexane, 3-methyl hexane, octane, 2-octene, nonane, decane, undecene, 2,6-dimethylundecane, dodecane, tridecane, tetradecane, pentadecane, hexadecane, heptadecane. In spite of being a large group, they are not potent odorants. (Carrapiso et al., 2002).

58 aromatic and cyclic hydrocarbons have been detected (Table 3). Seventeen of them: methyl cyclopentane, methyl benzene, ethyl benzene, propyl benzene, 1,2-dimethtylbenzene, 1,3-dimethylbenzene, p-xylene, 1,2,3-trimethylbenzene, 1,2,4-trimethylbenzene, 1,3,5-trimethylbenzene, 1-ethyl-4methylbenzene, 4-ethyl-1,2-dimethylbenzene, 2-ethenylcyclohexane, tetramethylbenzene, heptylbenzene, 2-pentylfurane and styrene have been detected by more than 3 authors [Sabio et al., 1998; Ramírez and Cava, 2007; Narváez-Rivas et al., 2010a, 2010b; Timón et al., 2002; Sánchez-Peña et al., 2005; Andrés et al., 2007; López et al., 1992; Timón et al., 1998; Jurado et al., 2009; García-González et al., 2008; Timón et al., 2001; Ruiz et al., 2001; Andrés et al., 2002; Andrade et al., 2009).

Several authors (Ramírez and Cava, 2007; Toldrá, 1998; López et al., 1992; García et al., 1991; González and Ockerman, 2000; Martín et al., 2006) have reported that hydrocarbons are probably products derived from the oxidative decomposition of lipids, which may be catalyzed by hemocompounds such as hemoglobin and myoglobin.

The 2-pentylfurane content was studied by Andres et al. (2007) in hams processed according to a modified system, and significant differences were observed. This compound was highly concentrated in hams processed with a modified system (with lower temperatures at the drying stage). The salt level also affected the content of 2-pentylfurane at day 177 , those hams with a higher salt content and lower content of this compound (Andrés et al., 2007).
The large quantities of branched alkanes found in the aged hams could potentially be interesting because very few branched hydrocarbons have been reported in studies of other cured meat volatiles (Berdagué et al., 1991; Gray and Pearson, 1984). As these molecules are also found in fresh meats (Shahidi et al., 1986), one possible source of them might be the unsaponifiable fraction from the feed of Iberian pigs (acorn and other vegetable products). These compounds have been used to discriminate hams according to the fattening system and five compounds (2,4-dimethyl-heptane, 2-octene, 2,2,5,5-tetramethylhexane, dodecane, 2,4,6-trimethyl-heptane and germacrane B) which show significant differences between hams from "Montanera" and "Cebo" (NarváezRivas et al., 2010b). On the other hand, the contents in 2,2,4,6,6-pentamethyl-heptane, m-xylene, 2,4-dimethyl-heptane, 6-methyl-tridecane, o-xylene and 2,6-dimethyl-undecane allow the differentiation of three fattening diets (Montanera, extensive cebo and intensive cebo), together with 1-metoxy2-propanol, isopropyl alcohol, 3-ethyl-2,2-dimathyloxirane, 3-methyl-3-pentanol and limonene (NarváezRivas et al., 2011). At any rate, it is believed that saturated and unsaturated hydrocarbons do not play a significant role in the flavor of meat (Min et al., 1979).

Martín et al. (2006) suggested that methyl hydrocarbons could be synthesized by molds as a product of secondary degradation of triglycerides.

\subsection{Aldehydes}

A total of 41 aldehydes have been identified in the Iberian ham volatile compounds (see Table 4). These carbonyl compounds play an important role in the aroma of the dry-cured ham because they have a low perception threshold.

The important linear aldehydes which have been detected in several studies are: butanal, pentanal, hexanal, heptanal, 2-heptenal, 2,4-nonadienal, octanal, 2-octenal, nonanal, 2-nonenal, decanal, 2-decanal, 2,4-decadienal, 2-undecenal and dodecenal (Sabio et al., 1998; Ramírez and Cava, 2007; Carrapiso et al., 2002; Timón et al., 2002; Sánchez-Peña et al., 2005; 
Table 4

Volatile aldehydes, ketones and alcohols previously reported in dry-cured Iberian ham

\begin{tabular}{|c|c|}
\hline Aldehydes & 3-Decen-2-one ${ }^{9}$ \\
\hline Acetaldehyde ${ }^{1,11}$ & 2-Decanone ${ }^{14,18}$ \\
\hline 2-Methyl propanal $\left.\right|^{1,2,3,11,16-18,19}$ & Dihydro-2(3H)-furanone $e^{2,11,17}$ \\
\hline Butanal $^{5,9,10,14,18,16,19}$ & 5-Ethyldihydro-2(3H)-furanone ${ }^{2,11,13,16}$ \\
\hline 3-Methyl butanal $\left.\right|^{1,2,3,5,7,8,9-16,18,19}$ & 5-Butyldihydro-2(3H)-furanone $\mathrm{f}^{11,16}$ \\
\hline 2-Methyl butanal ${ }^{1,2,3,5,8,9-11,13-16,18,19}$ & Dihydro-5-pentyl-2(3H)-furanone ${ }^{16}$ \\
\hline 3-Methyl-2-butenal ${ }^{4,5,14,17}$ & 6,10-Dimethyl-(E)5,9-undecadien-2-one ${ }^{16}$ \\
\hline 2-Methylbutenal ${ }^{15,17}$ & 2,6-bis(1,1-dimethyl)-2,5-cyclohexadiene-1,4-dione ${ }^{16}$ \\
\hline 4-Methyl-2-pentenal ${ }^{4}$ & 2,6-bis(1,1-dimethylethyl)-2,5-cyclohexadiene-1,4-dione ${ }^{19}$ \\
\hline 2-Methyl-2-pentenal ${ }^{4}$ & 5-Methyl-2-(1-methyl-ethyl)-cyclopentanone ${ }^{13}$ \\
\hline Pentanal $\left.\right|^{1,2,3-5,7,9,10,11,13,14,16,17,18}$ & Alcohols \\
\hline Hexanal $^{1,2,3-8,9-18}$ & Ethanol $^{1,2,4,7,12,14,17,18,19}$ \\
\hline 2-Hexenal $\left.\right|^{3,4,13}$ & 2-Etoxy-etanol ${ }^{13}$ \\
\hline 3-Hexenal ${ }^{3}$ & Propanol ${ }^{17,18}$ \\
\hline Heptanal $\left.\right|^{1,2,3-8,9-18}$ & 2-Propanol $\left.\right|^{2,4-7,12-14,16}$ \\
\hline 2-Meptenal| $2,3,5,12-15,17,18$ & 1,2-propanediol ${ }^{17}$ \\
\hline 2,4-Heptadienal ${ }^{13}$ & 2-Methyl propanol ${ }^{1,12,15,18,19}$ \\
\hline 1-Ethyl-2-methyl cyclopentane ${ }^{1}$ & 2-Methyl-2-propanol ${ }^{19}$ \\
\hline 1-Ethyl-3-methyl cyclopentane ${ }^{6}$ & 2-Aminopropanol ${ }^{17}$ \\
\hline Methional $^{3,16}$ & 1-Methoxy-2-propanol ${ }^{6}$ \\
\hline Benzaldehyde ${ }^{1,4,7,9-12,15,16,18,19}$ & 3-Ethoxy-1-propanol ${ }^{17}$ \\
\hline Ethylbenzaldehyde ${ }^{19}$ & Butanol ${ }^{7,12,13,17}$ \\
\hline 2,4-Nonadienal ${ }^{1,5,14}$ & 2-Butanol ${ }^{12}$ \\
\hline Octanal $^{1,2,3-8,9,11-18}$ & 2-Methyl-3-buten-2-ol ${ }^{1}$ \\
\hline 2-Octenal $\left.\right|^{1,3,5,12-14,18}$ & 1-Penten-3-ol ${ }^{1,2,13-15,17,18}$ \\
\hline 2,4-Octadienal $\left.\right|^{5,14}$ & 1-Pentanol ${ }^{1,2,4-7,10-14,16-18,20}$ \\
\hline Phenylacetaldehyde $1,2,4,5,9,11,14,16,18,19$ & 2-Pentanol ${ }^{1,13}$ \\
\hline Nonanal ${ }^{1,2,4-8,9,10-14,16,17,18}$ & 1,3-Butanediol ${ }^{9}$ \\
\hline 2-Nonenal ${ }^{1,5,10,12-14,16-18}$ & 2,3-Butanediol $\left.\right|^{9,11}$ \\
\hline 6-Nonenal ${ }^{13}$ & 1,4-Butanediol ${ }^{20}$ \\
\hline Decanal $^{1,2,4,7,9,10,12,14,16-18}$ & Tetradecan-1-ol $\left.\right|^{10,16}$ \\
\hline 2-Furaldehyde ${ }^{4}$ & Hexadecanol $^{16}$ \\
\hline 2-Decenal ${ }^{4,5,13,14,16-18}$ & 3-Methyl butanol $\left.\right|^{1,2,4,7,9-12,14,18,19,20}$ \\
\hline 2,4-Nonadienal ${ }^{9,18}$ & 2-Methyl butanol ${ }^{1,4,10,11,14,15,18-20}$ \\
\hline 2,4-Decadienal $\left.\right|^{9,10,12,13,16-18}$ & 2-Methyl-2-butanol ${ }^{19}$ \\
\hline Undecanal $^{16}$ & 2,3-Dimethyl-2-butanol ${ }^{6}$ \\
\hline 2-Undecenal ${ }^{5,14,16-18}$ & 2-Methyl-3-buten-2-ol ${ }^{12}$ \\
\hline Dodecanal $^{4,9,14,16}$ & 3-Methyl-3-buten-2-ol ${ }^{14,15}$ \\
\hline 2-Dodecenal ${ }^{4}$ & 2-Methyl-1-pentanol ${ }^{19}$ \\
\hline Tetradecanal $^{18}$ & 2-Methyl-2-pentanol $\left.\right|^{6,19}$ \\
\hline Pentadecanal $^{16}$ & 3-Methyl-3-pentanol ${ }^{6}$ \\
\hline Hexadecanal $^{10}$ & 4-Methyl-2-pentanol ${ }^{9}$ \\
\hline Octadecenal $\left.\right|^{16,18}$ & 1-Hexanol ${ }^{1,2,4,7,9-15,18,20}$ \\
\hline 5-Ethylcyclopent-1-enecarboxaldehyde ${ }^{13}$ & $2-$ Hexen-1-ol ${ }^{13}$ \\
\hline Ketones & Ciclohexanol ${ }^{18,19}$ \\
\hline Propanone $e^{1,2,5,7,11,12,14,17,18,19}$ & cis-3-hexen-1-ol ${ }^{20}$ \\
\hline 2,3-Butanedione $e^{1,3,7,10,12,18}$ & 2-Methyl-3-hexanol ${ }^{17}$ \\
\hline
\end{tabular}




\begin{tabular}{|c|c|}
\hline Butanone $e^{1,2,7,10,12,13,17,18,19}$ & 3-Methyl-3-hexanol ${ }^{19}$ \\
\hline 2-Pentanone $e^{1,2,3-5,11-15,17,18,19}$ & 2-Ethyl-1-hexanol ${ }^{9,13}$ \\
\hline 3-Pentanone ${ }^{12}$ & 2-Butoxiethanol ${ }^{10}$ \\
\hline 1-Hydroxy-2-propanone ${ }^{9}$ & Heptan-1-ol ${ }^{4,10,14,18}$ \\
\hline 3-Methylbutan-2-one ${ }^{10}$ & 2-Heptanol ${ }^{1,2,12}$ \\
\hline 3-Hydroxy-2-butanone $e^{2,9,10,17,18,19}$ & 3-Methyl-4-heptanol ${ }^{9}$ \\
\hline 3,3-Dimethyl-2-butanone ${ }^{19}$ & 4-Methyl-2-heptanol ${ }^{19}$ \\
\hline 1-Penten-3-one $e^{3,13}$ & 5-Methylheptan-2-ol ${ }^{20}$ \\
\hline 3-Penten-2-one ${ }^{1,9}$ & Ethyl phenol ${ }^{1}$ \\
\hline Pentan-2,3-dione $e^{5,10,14}$ & 1-Heptenol ${ }^{1}$ \\
\hline 4-Methyl-3-penten-2-one ${ }^{9,19}$ & 1-Octanol ${ }^{4,7,11,12,14,16-18,20}$ \\
\hline 3-Methyl-2-pentanone $e^{3,15,18,19}$ & 2-Butyl-1-octanol ${ }^{13}$ \\
\hline 3-Ethyl-cyclopentanone ${ }^{13}$ & 3,5-Octadien-2-ol ${ }^{13}$ \\
\hline Cyclopentanone $^{13}$ & 1-Octen-3-ol ${ }^{1,2,3,4,7,10-14,16-18,20}$ \\
\hline 3-Hexanone ${ }^{1,9}$ & Nonanol $^{12}$ \\
\hline 2-Hexanone ${ }^{1,2,5,14,15,17,18,19}$ & 8-Methyl-1,8-nonanediol ${ }^{19}$ \\
\hline 4-Hydroxy-4-methyl-2-pentanone ${ }^{9}$ & 4-Methyl-5-decanol ${ }^{13}$ \\
\hline Cyclohexanone $e^{1,9,18,19}$ & 1 -Decanol ${ }^{20}$ \\
\hline 4-Heptanone $\mathrm{e}^{1,9,17,18}$ & 2-Decen-1-ol ${ }^{13}$ \\
\hline 2-Heptanone $e^{1,2,3,5,7,8,9-18}$ & 1-Undecanol ${ }^{14}$ \\
\hline 4-Methyl-2-heptanone $e^{9,19}$ & Dodecanol $^{1,9,16,17,20}$ \\
\hline 3,5-Heptanedione ${ }^{5,14}$ & 4-Methylphenol ${ }^{17}$ \\
\hline 5-Hydroxy-3-methyl-3-hexanone ${ }^{9}$ & 3-Methylphenol ${ }^{15}$ \\
\hline 1-Octen-3-one ${ }^{3}$ & 2-Ethylphenol ${ }^{13}$ \\
\hline 3-Octen-2-one $e^{4,5,14}$ & 3-Ethylphenol ${ }^{15}$ \\
\hline 4-Octen-3-one ${ }^{1,13}$ & Benzyl alcohol ${ }^{16}$ \\
\hline 6-Octen-2-one ${ }^{13}$ & Benzenemethanol ${ }^{9,11,18}$ \\
\hline 6-Methyl-5-hepten-2-one $e^{1,13,16}$ & 4-Ethyl-1,3-benzenediol ${ }^{19}$ \\
\hline 3-Methyloctan-3-one ${ }^{10}$ & Phenylethanol $\left.\right|^{9-11,16,18,19}$ \\
\hline 2-Octanone $e^{1,2,5,7,8,12-15,17,18}$ & $\mathrm{BHT}^{10,16}$ \\
\hline 3-Octanone $e^{5,12,15}$ & 2,4-bis(1,1-dimethylethyl)phenol ${ }^{19}$ \\
\hline 2,3-Octanedieone $e^{2,5,14-17}$ & 3-Ethyl-2,2-dimethyl-oxirane ${ }^{6}$ \\
\hline 3,5-Octadien-2-one $e^{5,13,14}$ & 2-Hydroxymethyl-2,3,3,-trimethyl-oxirane ${ }^{13}$ \\
\hline 8-Nonen-2-one ${ }^{1,2}$ & Furfurylalcohol $^{20}$ \\
\hline 3-Nonen-2-one ${ }^{9}$ & Diethylenglycol ${ }^{18}$ \\
\hline 2-Nonanone $e^{1,2,7,12-14,16-18}$ & \\
\hline
\end{tabular}

In references: 1: Sabio et al., 1998; 2: Ramírez and Cava, 2007; 3: Carrapiso et al., 2002; 4: Narváez-Rivas et al., 2010b; 5: Timón et al., 2002; 6: Narváez-Rivas et al., 2011; 7: Sánchez-Peña et al., 2005; 8: Andrés et al., 2007; 9: Timón et al., 1998; 10: García et al., 1991; 11: Jurado et al., 2009; 12: García-González et al., 2008; 13: Narváez-Rivas et al., 2010a; 14: Timón et al., 2001; 15: Ruiz et al., 1999; 16: Ruiz et al., 1998a; 17: Ruiz et al., 2001; 18:Andrés et al., 2002; 19: Andrade et al., 2009, 20: López et al., 1992.

Andrés et al., 2007; López et al., 1992; Timón et al., 1998; García et al., 1991; Jurado et al., 2009; GarcíaGonzález et al., 2008; Narváez-Rivas et al., 2010a; Timón et al., 2001; Ruiz et al., 2001; Andrés et al., 2002; Andrade et al., 2009). These types of aldehydes come mainly from an oxidative degradation of the unsaturated fatty acids: oleic, linoleic, linolenic and arachidonic (Sabio et al., 1998; Frankel et al., 1981; Chan and Coxon, 1987).

On the other hand, the major formation pathway of the branched chain aldehydes seems to be the oxidative deamination-decarboxylation, probably via Strecker-degradation. The branched chain aldehydes detected in Iberian ham by numerous authors were: 2-methyl propanal, 3-methyl butanal, 3-methyl-2butenal, benzaldehyde and phenylacetaldehide (Sabio et al., 1998; Ramírez and Cava, 2007; Carrapiso et al., 2002; Timón et al., 2002; SánchezPeña et al., 2005; Andrés et al., 2007; López et al., 1992; Timón et al., 1998; García et al., 1991; Jurado et al., 2009; García-González et al., 2008; Timón et al., 2001; Andrés et al., 2002; Andrade et al., 2009). 
Hams from pigs fed on concentrate feeds with $\alpha$-tocopherol supplementation present the lowest concentrations of aldehydes, since the most abundant aldehydes (hexanal and pentanal) are found in low quantities in these hams (Timón et al., 2002). These low concentrations could be due to the delayed formation of these aldehydes during maturation owing to the $\alpha$-tocopherol action that would affect polyunsaturated fatty acids (PUFAs) (Timón et al., 2002; Mitsumoto et al., 1993). The antioxidant effect would be reduced by the largest percentages of PUFAs in the subcutaneous fat of "Montanera" hams, since these fatty acids are the most susceptible to oxidation (Wang et al,, 1996).

Hexanal, heptanal, octanal, nonanal, 3-methylbutanal, and 2-methylbutanal have been used to study the effect of salt content and processing condition during the ripening of Iberian ham (Andrés et al., 2007). Salt level did not significantly affect hexanal content at any of the samplings days. The type of processing significantly affected octanal and nonanal contents at day 163 (drying stage), and heptanal, octanal and nonanal contents at days 219 and 252 of processing. The type of processing has a significant effect in 2-methylbutanal content, those hams elaborated with lower temperatures at the drying stage showed lower levels on days 163 and 177 and higher levels on day 308. However, the 3-methylbutanal did not change with the type of processing. Moreover, the effect of salt level on the amount of these two aldehydes was also studied but no significant differences were found.

The pig genotype affects (E)-hepten-2-al and octanal (which adds pleasant notes to the aroma of dry-cured products), showing the highest contents in hams from ${ }^{\lambda}$ lberian $x$ o oDuroc (this last genotype corresponding to pigs selected for the production of dry-cured meat products, with a high level of fattening) (Ramírez and Cava, 2007).

Ripening time had a marked effect on 2-methylpropanal and 2-methylbutanal, whose abundances increased throughout processing (Jurado et al., 2009), and a positive and significant correlation between 2-methylbutanal and cured flavor was found (Dumont and Ada, 1972). In the finished product, 3-methylbutanal was found to be the most abundant volatile compound (Jurado et al., 2009).

No significant effect of the feeding system on lipid oxidation aldehydes (such as hexanal, heptanal, octanal and nonanal) was found (Jurado et al., 2009). However, acetaldehyde, which has been identified as an odorant of Iberian ham, was affected by the feeding system, being more abundant in Cebo hams than in Montanera (Jurado et al., 2009).

Nonanal is the most important aldehyde derived from oleic acid (Grosch, 1987) and it is in higher concentrations in "montanera" hams than in "cebo" hams. Moreover, other alehydes like 2- and 3-methylbutanal, related to the aged flavor of hams (Chan and Coxon, 1987), present the highest contents in the "montanera" hams (Ruiz et al., 2001).
Although some authors have suggested a microbial origin for 3- and 2-methylbutanal, the Strecker degradation of leucine and isoleucine respectively appears to be the more probable source for these compounds in dry-cured ham (Andrés et al., 2007).

Perhaps these are the compounds that have a higher number of possible ways of formation. Linear chain aldehydes could be formed by the breakdown of hydroperoxydes derived from unsaturated fatty acids (Sabio et al., 1998; Sánchez-Peña et al., 2005; García et al., 1991; González and Ockerman, 2000). Other aldehydes found in ham probably have different origins, such as the products of lipid degradation (Ramírez and Cava, 2007; Toldrá, 1998; SánchezPeña et al., 2005; García et al., 1991; Timón et al., 2001; González and Ockerman, 2000), proteins and carbohydrates (López et al., 1992; García et al., 1991; González and Ockerman, 2000). According to several authors (Sabio et al., 1998; Ramírez and Cava, 2007; Sánchez-Peña et al., 2005; Andrés et al., 2007; López et al., 1992; García et al., 1991; Zhang and Pawliszyn, 1993; González and Ockerman, 2000; Martín et al., 2006; Grosch, 1987; Ventanas et al., 2007), the main route of formation for branched chain aldehydes, such as 2-methyl-butanal, 3-methyl-butanal and phenyl acetaldehyde, seems to be the oxidative deaminationdecarboxylation of amino acids via Strecker degradation, suggesting that the Maillard reaction could be the principal vector by which these compounds are generated. In addition, some studies (Dumont and Ada, 1972; Martín et al., 2006) propose that microorganisms play an important role in the formation of these branched aldehydes, with microbial activity being other possible origin.

\subsection{Ketones}

Forty-eight ketones have been identified (see Table 4). But only 20 of them have been detected by the majority of authors (Sabio et al., 1998; Ramírez and Cava, 2007; Carrapiso et al., 2002; Timón et al., 2002; Sánchez-Peña et al., 2005; López et al., 1992; Timón et al., 1998; García et al., 1991; Jurado et al., 2009; García-González et al., 2008; Timón et al., 2001; Ruiz et al., 2001; Andrés et al., 2002; Andrade et al., 2009): propanone, 2,3-butanodione, butanone, 2-pentanone, 3-hidroxy-2-butanone, pentan 2,3-dione, 3-methyl-2-pentanone, 2-hexanone, cyclohexanone, 4-heptanone, 2-heptanone, 2-octanone, 3-octanone, 2,3-octanedione, 3,5-octadien-2-one, 2- nonanone, dihydro-2(3H)-furanone, 5-ethyldihydro-2(3H)-furanone.

The contents of 2-heptanone and 2-octanone were used to study the effect of processing type at different stages of ripening from dry-cured Iberian ham and it was observed that the processing system significantly affected the content of 2-heptanone and 2-octanone at day 219. Hams elaborated using a modified process (with lower temperatures at the drying stage) showed higher contents of these compounds than those processed under a traditional system. The origin of 2-heptanone and 2-octanone is the oxidation and decarboxilation of lipids (Berdagué et al., 1991). 
1-Etoxy-heptan-2-one was affected by the genotype of animals, showing the highest contents hams from Jlberian $x$ 이uㅡ, this last genotype corresponding to pigs selected for the production of dry-cured meat products, with a high level of fattening (Ramírez and Cava, 2007).

Ketones are basically present as methyl-ketones, which are products either of $\beta$-keto acid decarboxylation (Toldrá, 1998; Andrés et al., 2007; González and Ockerman, 2000) or of saturated fatty acid $\beta$-oxidation (Ramírez and Cava, 2007; Toldrá, 1998; Andrés et al., 2007; Timón et al., 2001; González and Ockerman, 2000). These compounds may also result from free fatty acid chemical oxidation (auto-oxidation) (Ramírez and Cava, 2007). In accordance with Sabio et al. (1998) and Sánchez-Peña et al. (2005), this last case occurs when the microbial population is small.

\subsection{Alcohols}

As can be observed, the major group was the alcohols from a quantitative point of view. A total of 66 different alcohols have been detected. Most of them have been previously detected by only 1 or 2 authors (Table 4). There are various alcohols: ethanol, 2-propenol, 1-penten-3-ol, 1-pentanol, 3-methyl-butanol, 1-hexanol, 1-heptanol, 2-heptanol, 1-octen-3-ol, dodecanol, phenylethanol and benzemethanol that have been identified in most of the articles (Ramírez and Cava, 2007; Timón et al., 2002; Sánchez-Peña et al., 2005; López et al., 1992; García et al., 1991; Jurado et al., 2009; García-González et al., 2008; Narváez-Rivas et al., 2010a; Timón et al., 2001; Ruiz et al., 2001; Andrés et al., 2002).

Usually, the aroma of these compounds is very pleasant, with fruity and floral notes. Their odor threshold value is usually higher than, for example, aldehydes so their influence in the aroma must be lower. However, unsaturated alcohols, such as 1-penten-3-ol and 1-octen-3-ol, each had a lower threshold value; they may play an important role in odor (Sabio et al., 1998). In particular, 2-propanol, the most abundant alcohol obtained, has been related to longer-ripened hams (Timón et al., 2001).

Pig genotype affects the content of hexan-1-ol, with hams from ôlberian $x$ 임oc showing the highest content (this last genotype corresponding to the pigs selected for the production of dry-cured meat products, with a high level of fattening) (Ramírez and Cava, 2007). 2-Methyl-1-butanol and benzene methanol were significantly affected by ripening time, being more abundant at the end of the process (Jurado et al., 2009). On the other hand, 1-octen-3-ol (which is an odor-active compound, was affected by the feeding system, being more abundant in "Montanera" hams (Jurado et al., 2009). As mentioned above, others alcohols (such as 1-methoxy-2-propanol, isopropyl alcohol and 3-methyl-3-pentanol) together with other compounds allow for the differentiation between Montanera, extensive cebo and intensive cebo feeding (Narváez-Rivas et al., 2011).

Linear alcohols are products of the oxidative decomposition of lipids, according to several authors (Ramírez and Cava, 2007; Toldrá, 1998; Sánchez-Peña et al., 2005; López et al., 1992; García et al., 1991). The branched alcohols may come from either a reduction in branched aldehydes (Martín et al., 2006) or a catabolism of amino acids (Dumont and Ada, 1972), such as phenylalanine, by means of Strecker degradation reactions (Ramírez and Cava, 2007; García et al., 1991; Timón et al., 2001). In accordance with Sánchez-Peña et al. (2005), microorganisms can act on 3-methyl butanal formed by the Strecker degradation of amino acids during proteolysis to give rise to 3-methyl-1-butanol. In addition, Sabio et al. (1998) told that a microbial activity could be involved.

\subsection{Esters and ethers}

While 51 ether and esters have been identified, only two esters have been detected by 3 authors at least, they are: ethyl-2-methyl butanoate, and ethylhexanoate (Sabio et al., 1998; López et al., 1992; Timón et al., 1998; García et al., 1991). The rest of the esters and ethers have been identified by only 1 or 2 authors (see Table 5).

Hexanoic acid-1-methylethyl ester and butanoic acid-1-methylethyl ester were affected by genotype, hams from ôlberian $x$ ㅇDuroc showing the highest contents (this last genotype corresponding to pigs selected for the production of dry-cured meat products, with a high level of fattening) (Ramírez and Cava, 2007). Hams from the genotype Olberian $x$ JDuroc showed the significantly highest content of butanoic acid-1-methylethyl ester (Ramírez and Cava, 2007). Moreover, 3-ethyl-2,2-dimethyl-oxirane together with other volatiles can differentiate between different fattening diets (Montanera, extensive cebo and intensive cebo) (Narváez-Rivas et al., 2011).

Probably, esters arise from the esterification of several alcohols and carboxylic acids (Sabio et al., 1998; Ramírez and Cava, 2007; Toldrá, 1998; López et al., 1992; García et al., 1991; Martín et al., 2006). There are authors (Ramírez and Cava, 2007) who do not rule out that the action of microorganisms is involved in the formation of esters. They have fruity notes, mainly those formed from short-chain acids. Esters with long-chain acids have a slight fatty odor.

\subsection{Lactones}

Although 8 lactones have been identified (see Table 5), only three of them have been detected by more than one author. These lactones are: $\gamma$-butyrolactone, $\gamma$-octalactone, $\gamma$-nonalactone and were observed by Andrés et al. (2007), López et al. (1992), Timón et al. (1998), García et al. (1991) and Andrés et al. (2002).

The influence of the processing system on the content of $\gamma$-octalactone was significant on days 163 , 191(drying stage), 219 and 308 (cellar stage) (Andrés et al., 2007). The trends were similar to those of 2-pentylfuran: Higher amounts of $\gamma$-octalactone during the drying phase and initial days of the cellar stage 
Table 5

Volatile esthers, ethers, lactones, terpenes, carboxylic acids and chloride, nitrogenous and sulphur compounds previously reported in dry-cured Iberian ham

\begin{tabular}{|c|c|}
\hline Esthers and ethers & Chloride compounds \\
\hline Ethyl acetate ${ }^{1,19}$ & Dichloromethane $e^{18,19}$ \\
\hline Methyl carbamate ${ }^{9}$ & Trichloromethane ${ }^{11,19}$ \\
\hline Linalyl acetate ${ }^{9}$ & Trichloroethane ${ }^{16}$ \\
\hline Butyl acetate ${ }^{13,16}$ & Tetrachloroethane $^{16}$ \\
\hline Ethyl propanate ${ }^{1}$ & 2,2-Dichloroethanol ${ }^{17}$ \\
\hline 2-Ethyl-hexyl-2-propenoate ${ }^{5,14}$ & 2-Chloronaphthalene ${ }^{11}$ \\
\hline 2-Methyl propanoate ${ }^{10}$ & Chloroform ${ }^{10,17,18,20}$ \\
\hline Ethyl 2-methyl propanoate ${ }^{1,3}$ & Nitrogenous compounds \\
\hline Ethyl 2-methyl butanoate $1,11,16$ & $N$-Methylene ethenamine $e^{1,16}$ \\
\hline Methyl butanoate ${ }^{16}$ & 2-Nitrobutane ${ }^{17}$ \\
\hline Acetic acid ethyl ester ${ }^{18}$ & 2-Propionyl-1-pyrroline ${ }^{3}$ \\
\hline Acetic acid butyl ester ${ }^{18}$ & 2-Acetyl-1-pyrroline ${ }^{3}$ \\
\hline Butanoic acid methyl ester ${ }^{18}$ & Pyrrol $^{1,14}$ \\
\hline Butanoic acid 1-methylethyl ester ${ }^{2}$ & Pyridine P,19 $^{2,19}$ \\
\hline Hexanoic acid methyl ester ${ }^{18}$ & Piperidine $^{14}$ \\
\hline Ethyl 3-methyl butanoate ${ }^{1,16}$ & Methane-1,1-(bis)-methylthio ${ }^{16,18}$ \\
\hline 3-Methylbutyl acetate ${ }^{16,19}$ & 2-Ethenyl-pyridine ${ }^{14}$ \\
\hline 1-Penten-3-ol acetate ${ }^{1}$ & Dibutylamine $^{19}$ \\
\hline 2-Methylpropyl acetate ${ }^{16}$ & 3-Methylbutamine ${ }^{10}$ \\
\hline Methyl hexanoate ${ }^{1,16}$ & Cyclobutylamine $^{6}$ \\
\hline Ethyl hexanoate $e^{1,9,11,14,16}$ & Phenylethylamine ${ }^{9,19}$ \\
\hline Ethyl-2-metylbutyrate ${ }^{3}$ & 4-Methylpentanenitrile ${ }^{17}$ \\
\hline Hexyl butyrate $^{9}$ & Hexanenitrile $1,14,16$ \\
\hline Propanoic acid, 2-methyl-1-(1,1-dimethylethyl)-2-methyl-1,3-propanediyl ester ${ }^{20}$ & 2,6-Dimethyl pyrazine ${ }^{2,12,17,19}$ \\
\hline Hexanoic acid 1-methylethyl ester ${ }^{2}$ & 3-Ethyl-2,6-dimethyl pyrazine ${ }^{17}$ \\
\hline 1,2-Benzenedicarboxylic acid, dibutyl ester ${ }^{20}$ & Trimethylpyrazine ${ }^{2}$ \\
\hline 1,2-Benzenedicarboxylic acid, butyl 2-methylpropyl ester ${ }^{20}$ & 3,5-Dimethylisoxazole ${ }^{16}$ \\
\hline 1,2-Benzenedicarboxylic acid, bis(2-methylpropyl) ester ${ }^{20}$ & N,N-Dimethyl-2-buthoxi-Isopropylamine ${ }^{14}$ \\
\hline 1,2-Benzenedicarboxylic acid, bis(2-methoxyethyl) ester ${ }^{20}$ & Hexadecanonitrile ${ }^{17}$ \\
\hline 1,4-Benzenedicarboxylic acid, dimethyl ester ${ }^{20}$ & Acetamide ${ }^{17}$ \\
\hline 1-Methoxy-pentane ${ }^{14}$ & Propanodiamide ${ }^{9}$ \\
\hline Ethyl heptanoate ${ }^{1}$ & Isovaleramide ${ }^{9}$ \\
\hline Ethyl octanoate ${ }^{1,11}$ & Sulphur compounds \\
\hline Propyloctanoate ${ }^{17}$ & Dimethylsulphide ${ }^{19}$ \\
\hline Methyl decanoate ${ }^{17}$ & Diphenylsulphide ${ }^{19}$ \\
\hline Ethyl decanoate ${ }^{11,17}$ & Hidrogen sulphide ${ }^{3}$ \\
\hline Propyl decanoate ${ }^{17}$ & Carbon disulphide $1,6,14,17,20$ \\
\hline Butyl decanoate ${ }^{17}$ & Dimethyl disulphide $e^{1,12-14,16-19,20}$ \\
\hline Ethyl tetradecanoate ${ }^{17}$ & Dimethyl trisulphide ${ }^{1,3,16,17,20}$ \\
\hline Pyrrol & Dimethyl tetrasulphide ${ }^{17}$ \\
\hline Pyridine $e^{2,19}$ & Diprophenyldisulphide ${ }^{2,5}$ \\
\hline Piperidine $^{14}$ & Methyl $n$-pentyl disulphide ${ }^{1}$ \\
\hline
\end{tabular}




\begin{tabular}{|c|c|}
\hline Ethyl hexadecanoate ${ }^{11}$ & Methyl $n$-hexane disulphide ${ }^{1}$ \\
\hline Dimethyl phthalate ${ }^{17}$ & 3-Methylthio propanol $\left.\right|^{11,20}$ \\
\hline Diethyl phthalate ${ }^{17}$ & 3-Methylthio propanal ${ }^{2,5,12,20}$ \\
\hline 2-Ethoxyethoxy ethanol ${ }^{11}$ & Methane-1,1-(bis)-methylthio ${ }^{16,18}$ \\
\hline Phthalic acid alkyl ester ${ }^{11}$ & Benzothiazole ${ }^{19}$ \\
\hline Phthalic acid alkyl ester ${ }^{11}$ & Ethanethioc acid, methyl ester ${ }^{5}$ \\
\hline Hexyl octyl ether ${ }^{14}$ & 2-Methyl-3-furanthiol ${ }^{3}$ \\
\hline Diethyl ether ${ }^{19}$ & 2-Furfurylthiol ${ }^{3}$ \\
\hline Eucalyptol $^{14}$ & Methanethiol $\left.\right|^{3,12,18,20}$ \\
\hline Di-(3-methyl-buthyl)ether ${ }^{14}$ & Carboxylic acids \\
\hline 2-D-2-pentadecyl-1,3-dioxolane ${ }^{14}$ & Acetic acid ${ }^{2,9,10,12,17-19}$ \\
\hline Lactones & Propanoic acid $^{10}$ \\
\hline$\gamma$-Butyrolactone $e^{9,10,11,19}$ & 2-Methylpropanoic acid ${ }^{2,13,19}$ \\
\hline$\gamma$-Valerolactone ${ }^{11}$ & Butanoic acid ${ }^{2,7,9,10,12-14,18,19}$ \\
\hline$\gamma$-Hexalactone ${ }^{11}$ & 2-Methylbutanoic acid ${ }^{2,10,17-19,20}$ \\
\hline$\delta$-Hexalactone ${ }^{19}$ & 3-Methylbutanoic acid ${ }^{2,10,12,17-19}$ \\
\hline$\beta$-Octalactone ${ }^{18}$ & Pentanoic acid ${ }^{9,10}$ \\
\hline$\gamma$-Octalactone $e^{8,11,19}$ & Hexanoic acid $2,7,9,10,18,19$ \\
\hline$\gamma$-Nonalactone $e^{11,19}$ & 2-Methylhexanoic acid ${ }^{19,20}$ \\
\hline$\gamma$-Lactone ${ }^{17}$ & Isohexanoic acid ${ }^{9}$ \\
\hline Terpenes & Heptanoic acid ${ }^{10,18,19}$ \\
\hline Canphene $^{1}$ & Octanoic acid ${ }^{2,9,10,18,19}$ \\
\hline$\beta$-Phelandrene ${ }^{1}$ & Isooctanoic acid ${ }^{9}$ \\
\hline 3-Carene ${ }^{1,17,19}$ & Benzoic acid $^{10}$ \\
\hline 4-Carene $e^{4,14}$ & Nonanoic acid ${ }^{10,18,19}$ \\
\hline Limonene $e^{1,2,4-7,10,13-17,19}$ & Decanoic acid ${ }^{10,18,19}$ \\
\hline Cineol $^{1}$ & Dodecanoic acid ${ }^{10,18,19}$ \\
\hline$\beta$-pinene $e^{5,15,16}$ & Tetradecanoic acid ${ }^{10}$ \\
\hline \multirow[t]{3}{*}{$\alpha$-pinene $e^{13,5,16,17,19}$} & Pentadecanoic acid ${ }^{11}$ \\
\hline & 4-Hydroxybenzenesulfonic acid ${ }^{17}$ \\
\hline & Benzenedicarboxylic acid ${ }^{10}$ \\
\hline
\end{tabular}

In references: 1: Sabio et al., 1998; 2: Ramírez and Cava, 2007; 3: Carrapiso et al., 2002; 4: Narváez-Rivas et al., 2010b; 5: Timón et al., 2002; 6: Narváez-Rivas et al., 2011; 7: Sánchez-Peña et al., 2005; 8: Andrés et al., 2007; 9: López et al., 1992; 10: Timón et al., 1998; 11: García et al., 1991; 12: Jurado et al., 2009; 13: García-González et al., 2008; 14: Narváez-Rivas et al., 2010a; 15: Timón et al., 2001; 16: Ruiz et al., 1999; 17: Ruiz et al., 1998a; 18: Ruiz et al., 2001; 19: Andrés et al., 2002; 20: Andrade et al., 2009.

and lower amounts in the final days of cellar. In modified and traditional systems, the effect of salt did not influence the content in $\gamma$-octalactone throughout the processing. Therefore, the type of processing did not affect the content of this compound (Andrés et al., 2007). $\gamma$-Octalactone may have different origins. The main origin of lactones is lipid oxidation (Slaughter, 1999), but Maillard reactions have also been proposed as a possible origin. Although their contribution to the aroma of these products has not yet been well established, in other products they show a great importance due to their aromatic notes described as fruity and very sweet, and their low olfaction threshold (Andrés et al., 2007; Duffose et al., 1994). According to Baines and Mlotkiewicz (1984), they would be related to buttery, oily, fatty, fruity and coconut-like flavors.

Lactones can be formed by lactonization (dehydration and cyclation) of hydroxyacids from fat, and also by oxidation of fatty acids and unsaturated aldehydes (García et al., 1991). Andrés et al. (2007) pointed out that the main origin of lactones is lipid oxidation, but the Maillard reaction is also proposed as a possible origin.

\subsection{Terpenes}

Eight terpenes have been found in Iberian ham (Table 5). 3-Carene, limonene, $\beta$-pinene, $\alpha$-pinene are the compounds detected by several authors 
(Sabio et al., 1998; Ramírez and Cava, 2007; Timón et al., 1998; García-González et al., 2008; Timón et al., 2001; Andrés et al., 2002; Andrade et al., 2009).

The presence of limonene and other terpenes is usually described in hams because these compounds are normal constituents of the unsaponifiable fraction of vegetable fat. Thus, they come from the feed and they are accumulated in the animal's body (Sabio et al., 1998; Ramírez and Cava, 2007; Timón et al., 2002; Sánchez-Peña et al., 2005). In fact, limonene, together with others volatile compounds, allows for the differentiation between the three types of fattening diets (Montanera, extensive cebo and intensive cebo) (Narváez-Rivas et al., 2011).

Although it is generally accepted that hydrocarbons do not contribute significantly to flavor, some terpenes (xylene, pinene and limonene) present very particular aromas such as sweet, woody or lemony (Timón et al., 2002).

\subsection{Nitrogenous compounds}

Twenty-three nitrogenous compounds have been detected as volatile compounds in Iberian ham (see Table 5). n-Methylene ethenamine, pyrrol, pyridine, phenylethylamine, hexenenitrile, 2,6-dimethyl pyrazine, trimethylpirazine were detected by two author at least (Sabio et al., 1998; Ramírez and Cava, 2007; López et al., 1992; Andrés et al., 2002; Andrade et al., 2009). The rest of nitrogenous compounds were detected by only one author.

2-Methylpyrazine has been affected by both ripening time and feeding system, so it could be used as indicator of both factors (Jurado et al., 2009).

Nitrile compounds have been detected in sausages (Stanhke, 1995) and nitrite-cured cooked pork (Mottram et al., 1984). The latter proposed their formation at the expense of the corresponding aldehydes during lipid oxidation involving nitrite. With respect to the volatile amines found, they are frequently cited as being of microbial origin in meat sausages (Dainty and Blom, 1995). However, amines can also originate from the decarboxylation of amino acids at a low $\mathrm{pH}$, as occurs in cheese (Belitz and Grosch, 1986). They can also be formed during the pyrolysis of amino acids (MacLeod and SeyyedainArdebii, 1981), but the temperatures reached during processing are not high enough to allow for such reactions. An increase in volatile basic nitrogen during the ripening of Iberian hams has been described previously (Ventanas et al., 1992), and López et al. (1992) have detected an amine in Iberian ham volatiles.

These compounds, such as pyrazines, are compounds found in many meats and meat products prepared by cooking at high temperatures (Mussinan and Walradt, 1974). The high temperature promotes a reaction between diketo compounds and amino compounds, leading to pyrazine formation (Shibamoto and Bernhard, 1976). However, during dry-cured ham processing low temperatures are used, so it is likely that the formation of these compounds is favored by the dehydration process (Sabio et al., 1998). Martín et al. (2006) suggest that pyrazines are generated by the microbial population.

These compounds come from the breakdown of proteins, free amino acids and nucleic acids (Sabio et al., 1998; Ramírez and Cava, 2007; Dumont and Ada, 1972). The presence of an oxazole in ham is surprising, considering that they normally are found only in heated meat (Chan and Coxon, 1987), several oxazoles have been described as nutty, sweet, green, woody, musty and vegetable-like (Mottram et al., 1984).

Three amides have been identified: Acetamide (Andrade et al., 2009), propanediamide and isovaleramide (López et al., 1992).

\subsection{Sulphur compounds}

A total of 18 sulphur compounds were detected (Table 5), but only 5 of them are commonly find in Iberian ham. They are: carbon disulphide, dimethyl disulphide, dimethyl trisulphide, 3-methylthio propanal, methanethiol.

Dimethyl disulphide was affected by ripening time and was not detected until day 230 of the process (Jurado et al., 2009).

These compounds may be derived from the catabolism of amino acids that contain sulfur (Sabio et al., 1998; Ramírez and Cava, 2007), ribonucleotides (Dumont and Ada, 1972) or generated by the microbial population (Martín et al., 2006).

1,1 (Bis)methylthiomethane has been found in canned beef, and is associated with other carbonyl and sulfur compounds, with the off-flavor of this heated product (Person and Von Sydow, 1973). Its origin might involve reactions between hydrogen sulfide and such compounds as ribonucleotides, but these types of reactions have only been described in heated model systems (Stanhke, 1995).

\subsection{Carboxylic acids}

This group is formed by 21 different compounds (see Table 5). Nevertheless, 11 carboxylic acids have been identified in more than one work. They are: acetic acid, 2-methylpropanoic acid, butanoic acid, 2-methylbutanoic acid, 3-methylbutanoic acid, hexanoic acid, heptanoic acid, octanoic acid, nonanoic acid, decanoic acid, dodecanoic acid b (Ramírez and Cava, 2007; Sánchez-Peña et al., 2005; López et al., 1992; Timón et al., 1998; Jurado et al., 2009; García-González et al., 2008; Narváez-Rivas et al., 2010a; Ruiz et al., 2001; Andrés et al., 2002; Andrade et al., 2009).

3-Methyl-butanoic acid showed differences among batches, with the Olberian $x$ ðDDuroc (corresponding to animals selected for meat production) genotype showing the significantly highest content of this compound (Ramírez and Cava, 2007).

Ramírez and Cava (Ramírez and Cava, 2007) show that, generally, these compounds are generated by reactions of lipid oxidation. The origin of acetic acid in ham is not clear. According to some authors, this is originated from carbohydrate fermentation by 
microorganisms (Kandler, 1983) and according to others from the Maillard reaction (Martín et al., 2006). Some branched acids have been identified in ham as a product of the microbial metabolism of amino acids (Ventanas et al., 2007). Other authors have attributed the origin of these compounds to the action of molds, like in the case of fermented meat products (Bruna et al., 2001). However, they could be also originated from the oxidation of their respective Strecker aldehydes, for example, 2-methyl butanal would come from the degradation of isoleucine amino acid and 2-methyl butanoic acid would be formed from oxidation (Ramírez and Cava, 2007).

\subsection{Chloride compounds}

Seven chloride compounds have been identified in Iberian ham (Table 5). Most of them have been detected by only one research group. Dichloromethane was detected by Ruiz et al. (2001) and Andrés et al. (2002). Chloroform is the compound of this group that has been identified in several articles (Timón et al., 1998; Ruiz et al., 2001; Andrade et al., 2009). The chloride compounds found have been related to pesticide residues in the feed (Flores et al., 1997), except Berdagué et al. (1991) who attributed them to laboratory contamination.

\section{CONCLUSIONS}

In summary, the volatile compounds from Iberian hams are affected by the following factors: rearing system, age of animal, genotype of pig and the conditions of the ripening process (salt content, length of process, processing conditions).

In this type of hams, the SPME and purge and trap techniques have been the most used to concentrate and isolate the volatiles. Then, these volatiles are analyzed by GC and detected by using a MS-detector, sniffing/olfactometry technique or a FID. Due to the different technique of isolation used, the volatile profile can change. In fact, the quantity of these compounds is very variable depending on the temperatures and times used in each phase of the isolation process. It would be very interesting to carry out new researches to establish the optimum parameters to obtain the best results for this kind of samples. Every aroma isolation task should be approached as a unique analysis.

It can be concluded that the origin of some compounds could come from lipolysis, chemical or enzymatic reactions, proteolysis, Strecker degradation and Maillard reaction. However, the origin of others is unknown. Thus, in order to know the processes by which the volatile compounds of dry-cured Iberian ham are generated, more research needs to be done using the same pieces during the dry-curing process.

\section{ACKNOWLEDGEMENTS}

This study was supported by projects P08-AGR03498 and P09-AGR-04789.

\section{REFERENCES}

Acree T, Arn H. 1997. Gas chromatography-olfactometry (GCO) of natural products. Flavornet. Available at http://www.nysaes.cornell.edu/flavornet/.

Andrade MJ, Córdoba JJ, Sánchez B, Casado, EM, Rodríguez M. 2009. Evaluation and selection of yeasts isolated from dry-cured Iberian ham by their volatile compound production. Food Chem. 113, 457-463.

Andrés Al, Cava R, Ruiz J. 2002. Monitoring volatile compounds during dry-cured ham ripening by solidphase microextraction coupled to a new directextraction device. J. Chromatogr. A. 963, 83-88.

Andrés Al, Cava R, Ventanas S, Muriel E, Ruiz J. 2007. Effect of salt content and processing conditions on volatile compounds formation throughout the ripening of Iberian ham. Eur. Food Res. Technol. 225, 677684.

Antequera T, López-Bote CJ, Córdoba JJ, García C, Asensio MA, Ventanas J, García-Regueiro J A, Díaz I. 1992. Lipid oxidative changes in the processing of Iberian pig hams. Food Chem. 45, 105-110.

Aparicio-Ruiz R, Morales MT. 1998. Characterization of olive ripeness by green aroma compounds of virgin olive oil. J. Agric. Food Chem. 46, 1116-1122.

Arthur CL, Pawliszyn J. 1990. Solid phase microextraction with thermal desorption using fused silica optical fibers. Anal. Chem.62, 2145-2148.

Arthur CL, Potter, DW, Buchholz KD, Motlagh S, Pawliszyn J. 1992. Solid-phase microextraction for the direct analysis of water: Theory and practice. LC-GC Int. 10, 656-661.

Baines DA, Mlotkiewicz JA. 1984. The chemistry of meat flavor. In A. J. Bailey (Ed.), Recent Advances in the Chemistry of Meat (pp. 118-164). Royal Society of Chemistry: London.

Belitz HD, Grosch W. 1986. Food Chemistry. Berlin: Springer.

Berdagué JL, Bonnaud N, Rousset S, Touraille C. 1993. Influence of pig crossbreed on the composition volatile compound content and flavour of dry cured ham. Meat Sci. 34, 119-129.

Berdagué JL, Denoyer C, Le Quere JL, Semon E. 1991. Volatile components of dry-cured ham. J. Agric. Food Chem. 39, 1257-1261.

Boren H, Grimvall A, Palmborg J, Sävenhed R, Wigilius B. 1985. Optimization of the open stripping system for the analysis of trace oranics in water. J. Chromatogr. 348, 67-78.

Bruna JM, Hierro EM, De la Hoz L, Mottram DS, Fernández M, Ordóñez JA. 2001. The contribution of Penicillium aurantiogriseum to the volatile composition and sensory quality of dry fermented sausages. Meat Sci. 59, 97-107.

Burger BV, Munro Z. 1987. Headspace gas analysis liquid desorption of headspace volatiles trapped on activated carbon open tubular traps. J. Chromatogr. 402, 95-103.

Buscailhon S, Berdagué JL, Monin G. 1993. Time-related changes in volatile compounds of lean tissue during processing of French dry-cured ham. J. Sci. Food Agric. 63, 69-75.

Carrapiso Al, García C. 2004. Iberian ham headspace: odorants of intermuscular fat and differences with lean. J. Sci. Food Agric. 84, 2047-2051.

Carrapiso Al, Martín L, Jurado A, García C. 2010. Characterisation of the most odour-active compounds of bone tainted dry-cured Iberian ham. Meat Sci. 85, 54-58.. 
Carrapiso AI, Ventanas J, García C. 2002. Characterization of the most odor-active compounds of Iberian ham headspace. J. Agric. Food Chem. 50, 1996-2000.

Cava R, Ruiz, J, Ventanas J, Antequera T. 1999. Oxidative and lipolytic changes during ripening of Iberian hams as affected by feeding regime: extensive feeding and alpha-tocopheryl acetate supplementation. Meat Sci. 52, 165-172.

Chan HWS, Coxon DT. 1987. Lipid hydroperoxides. In H. W. S. Chan (Ed.), Autoxidation of Unsaturated Lipids (pp. 17-51). New York: Academic Press.

Dainty R, Blom H. 1995. Flavour chemistry of fermented sausages. In F. Campbell-Platt, \& P. E. Cook (Eds.), Fermented meats (pp. 176-193). London: Blackie Academic and Professional.

Dirinck P, Van Opstaele F, Vandendriessche F. 1997. Flavour differences between northern and southern European cured hams. Food Chem. 59, 511-521.

Duffose L, Latrasse A, Spinnler HE. 1994. Importance des lactones dans les arômes alimentaires: structure, distribution, propriétés sensorielles et biosynthèse. Sci. Aliments. 14, 17-50.

Dumont JP, Ada J. 1972. Isolement des constituants de l'arôme des fromages: comparaison de methods. Lait $52,311$.

Flores J, Toldrá F. 1999. Curing: Processes and aplications. In R. Macrae, R. Robinson, M. Sadler, \& G. Fullerlove (Eds.), Encyclopedia of food science, food technology and nutrition (pp. 1277-1282). London: Academic Press.

Flores M. 1997. Mediterranean vs northern European meat products. Processing technologies and main differences. Food Chem. 59, 505-510.

Flores M, Grimm CC, Toldrá F, Spanier AM. 1997. "Correlations of sensory and volatile compounds of Spanish "Serrano" dry-cured ham as a function of two processing times". J. Agric. Food Chem. 45, 2178-2186.

Frankel EN, Neff WE, Selke E. 1981. Analysis of autoxidized fats by gas chromatography-mass spectrometry: VII. Volatile thermal decomposition products of pure hydroperoxides from autoxidized and photosensitized oxidized methyl oleate, linoleate and linolenate. Lipids, 16, 279-385.

García-González DL, Roncales P, Cilla I., Del Río S., Poma JP, Aparicio-Ruiz R. 2006. Interlaboratory evaluation of dry-cured hams (from France and Spain) by assessors from two different nationalities. Meat Sci. 73, 521-528.

García-González, DL, Tena N, Aparicio-Ruiz, R, Morales MT. 2008. Relationship between sensory attributes and volatile compounds qualifying dry-cured hams. Meat Sci. 80, 315-325.

García C, Berdagué JJ, Antequera T, López-Bote C, Córdoba JJ, Ventanas J. 1991. Volatile components of dry cured lberian ham. Food Chem. 41, 23-32.

González CB, Ockerman, HW. 2000. Dry-cured mediterranean hams: long process, slow changes and high quality: a review. J. Muscle Foods 11, 1-17.

Gray JI, Pearson AM. 1984. Cured meat flavor. Adv. Food Res. 29, 1-86.

Grosch W. 1987. Reaction of hydroperoxides-Products of low molecular weight. In H. W. S. Chan (Ed.), Autoxidation of unsaturated lipids (pp. 95). London: Academic Press.

Hinrichsen LL, Pedersen, SB. 1995. Relationship among flavor, volatile compounds, chemical changes, and microflora in Italian-type dry-cured ham during processing. J. Agric. Food Chem. 43, 2932-2940.

Jurado A, García C, Timón ML, Carrapiso Al. 2007. Effect of ripening time and rearing system on amino acid-related flavour compounds of Iberian ham. Meat Sci. 75, 585-594.

Jurado A, Carrapiso Al, Ventanas J, García C. 2009. Changes in SPME-extracted volatile compounds from Iberian ham during ripening. Grasas Aceites 60, 262272.

Kandler O. 1983. Carbohydrate metabolism in lactic acid bacteria. Anton. Van Leeuw. 49, 209-224.

Kerscher R, Grosch W. 1997. Comparative evaluation of potent odorants of boiled beef by aroma extract dilution and concentration techniques. $Z$. Lebensm. Unters. For. 204, 3-6.

Kondjoyan N, Berdagué JL. 1996. A compilation of relative retention indices of the analysis of aromatic compounds. Laboratoire flaveur, Station de recherches sur la viande, INRA: Theix, France.

Kovats E. 1965. Gas chromatographic characterization of organic substances in the retention index system. In J. C. Giddings, \& R. A. Keller, Adv. Chromatogr. (pp. 229-232). New York: Marcel Dekker.

López MO, de la Hoz L, Cambero MI, Gallardo E, Reglero G, Ordóñez JA. 1992. Volatile compounds of dry hams from Iberian pigs. Meat Sci. 31, 267-277.

MacLeod G, Seyyedain-Ardebii,M. 1981. Natural and simulated meat flavors (with particular reference to beef). Critical Rev. Food Sci. Nutrit. 14, 309-437.

Martín A, Córdoba JJ, Aranda E, Guía Córdoba M, Asensio MA. 2006. Contribution of a selected fungal population to the volatile compounds on dry-cured ham. Int. J. Food Microbiol. 110, 8-18.

Merkle JA, Larick DK. 1994. Concentration of beef fat volatiles with supercritical carbon dioxide. J. Food Sci. 59, 478-483.

Min DB. Ina K, Peterson RJ, Chang SS. 1979. Preliminary identification of volatile flavor compounds in the neutral fraction of roast beef. J. Food Sci. 44, 639-642.

Mitsumoto M, Arnold RN, Schaeffer DM, Cassens RC. 1993. Dietary versus postmortem supplementation of vitamin $E$ on pigment and lipid stability in ground beef. J. Animal Sci. 71, 1812-1816.

Mottram DS, Croft SE, Patterson RLS. 1984. Volatile components of cured and uncured pork: The role of nitrite and the formation of nitrogen compounds. J. Sci. Food Agric. 35, 233-239.

Mussinan CJ, Walradt JP. 1974. Volatile constituents of pressure cooked pork liver. J. Agric. Food Chem. 22, 827-831.

Narváez-Rivas M, Gallardo E, Ríos JJ, León-Camacho M. 2010a. A tentative characterization of volatile compounds from Iberian dry-cured ham according to different anatomical locations. A detailed study. Grasas Aceites, 61, 369-377.

Narváez-Rivas M, Pablos F, Jurado JM, León-Camacho M. 2011. Authentication of fattening diet of Iberian pigs according to their volatile compounds profile from raw subcutaneous fat. Anal. Bioanal. Chem. 399, 2115-2122.

Narváez-Rivas M, Vicario IM, Alcalde, MJ, León-Camacho M. 2010b. Volatile hydrocarbon profile of Iberian drycured hams. A possible tool for authentication of hams according to the fattening diet. Talanta, 81, 1224-1228.

Narváez-Rivas M, Vicario IM, Graciani Constante E, León-Camacho M. 2007. Changes in the concentrations of free fatty acid, monoacylglycerol and diacylglycerol in the subcutaneous fat of Iberian ham during dry-curing process. J. Agric. Food Chem. 55, 10953-10961.

Olafsdottir G, Steinke JA, Lindsay RC. 1985. Quantitative performance of a simple Tenax-GC adsorption 
method for use in the analysis of aroma volatiles. J. Food Sci. 50, 1431-1436.

Person T, Von Sydow E. 1973. Aroma of canned beef: gas chromatographic and mass spectrometric analysis of the volatiles. J. Food Sci. 38, 377-385.

Pillonel L, Bosset JO, Tabacchi, R. 2002. Rapid preconcentration and enrichment techniques for the analysis of food volatile: A review. Lebensm. Wiss. Technol. 35, 1-14.

Ramírez R, Cava R. 2007. Volatile profiles of dry-cured meat products from three different Iberian $X$ duroc genotypes. J. Agric. Food Chem. 55, 1923-1931.

Reindl B, Stan H-J. 1982. Determination of volatile aldehydes in meat as 2,4-dinitrophenylhydrazones using reversedphase high-performance liquid chromatography. J. Agric. Food Chem. 30, 849-854.

Reiners J, Grosch W. 1998. Odorants of virgin olive oils with different flavor profiles. J. Agric. Food Chem. 46, 2754-2763.

Rey Al, Daza A, López-Carrasco C, López-Bote CJ. 2006. Feeding Iberian pigs with acorns and grass in either freerange or confinement affects the carcass characteristics and fatty acids and tocopherols accumulation in Longissimus dorsi muscle and backfat. Meat Sci. $\mathbf{7 3}$, 66-74.

Ruiz J, Cava R, Ventanas J, Jensen MT. 1998. Headspace solid phase microextraction for the analysis of volatiles in a meat product: dry-cured Iberian ham. J. Agric. Food Chem. 46, 4688-4694.

Ruiz J, Ventanas J, Cava R. 2001. New device for direct extraction of volatiles in solid samples using SPME. J. Agric. Food Chem. 49, 5115-5121.

Ruiz J, Ventanas J, Cava R, Andrés A, García C. 1999. Volatile compounds of dry-cured Iberian ham as affected by the length of the curing process. Meat Sci. 52, 19-27.

Rychlik M, Schieberle P, Grosch W. 1998. Compilation of odor thresholds, odor qualities and retention indices of key food odorants. Germany: Deutsche Forschungsanstalt für Lebensmittelchemie.

Sabio E, Vidal-Aragón MC, Bernalte MJ, Gata JL. 1998. Volatile compounds present in six types of dry-cured ham from south European countries. Food Chem. 61, 493-503.

Sánchez-Peña CM, Luna G, García-González DL, Aparicio R. 2005. Characterization of French and Spanish dry-cured hams: influence of the volatiles from the muscles and the subcutaneous fat quantified by SPME-GC. Meat Sci. 69, 635-645.

Schomburg G, Husmann H, Schulz F, Teller G, Bender M. 1983. Cold sample injection with either the split or splitless mode of temperature-programmed sample transfer: Comparison to cold on-column injection with a commercial device. J. Chromatogr. 279, 259-267.

Shahidi F, Rubin LJ, D'Souza LA. 1986. Meat flavor volatiles: A review of the composition, techniques of analysis, and sensory evaluation. Crit. Rev. Food Sci. Nutr. 24, 147-243.
Shibamoto T, Bernhard RA. 1976. Effect of time, temperature, and reactant ratio on pyrazine formation in model systems. J. Agric. Food Chem. 24, 847-852.

Slaughter JC. 1999. The naturally occurring furanones: formation and function from pheromone to food. Biol. Rev. 74, 259-276.

Stanhke LH. 1995. Dried sausages fermented with Staphylococcus xylosus at different temperatures and with different ingredient levels - Part II. Volatile components. Meat Sci. 41, 193-209.

Timón ML, Martín L, Petrón MJ, Jurado A. García C. 2002. Composition of subcutaneous fat from drycured Iberian hams as influenced by pig feeding. J. Sci. Food Agric. 82, 186-191.

Timón ML, Ventanas J, Carrapiso Al, Jurado A, García C. 2001. Subcutaneous and intermuscular fat characterisation of dry-cured Iberian hams. Meat Sci. 58, 85-91.

Timón ML, Ventanas J, Martín L, Tejeda JF, García C. 1998. Volatile compounds in supercritical carbon dioxide extracts of Iberian ham. J. Agric. Food Chem. 46, 5143-5150.

Toldrá F. 1998. Proteolysis and lipolysis in flavour development of dry-cured meat products. Meat Sci. 49, S101-S110.

Toldrá F, Aristoy MC, Flores M. 2009. Relevance of nitrate and nitrite in dry-cured ham and their effects on aroma development. Grasas Aceites, 60, 291-296.

Van Deemter JJ, Zuiderweg FJ, Klinkenberg A. 1956. Longitudinal diffusion and resistance to mass transfer as causes of nonideality in chromatography. Chem. Eng. Sci. 5, 271-289.

Ventanas J, Córdoba JJ, Antequera T, García C, LópezBote C, Asensio MA. 1992. Hydrolysis and Maillard reactions during ripening of Iberian ham. J. Food Sci. 57, 813-815.

Ventanas S, Estévez M, Delgado CL, Ruiz J. 2007. Phospholipid oxidation, non-enzymatic browning development and volatile compounds generation in model systems containing liposomes from porcine Longissimus dorsi and selected amino acids. Eur. Food Res. Technol. 225, 665-675.

Wampler TP. 2002. Analysis of food volatiles using headspace-gas chromatography technique. In R. Marsili (Ed.), Flavor, Fragance and Odor analysis (pp. 25-55). New York: Marcel Dekker.

Wang YH, Leibholz J, Bryden WL, Fraser DR. 1996. Lipid peroxidation status as an index to evaluate the influence of dietary fats on vitamin $E$ requirements of young pigs. Brit. J. Nutr. 75, 81-95.

Washall JW, Wampler T. 1990. Sources of error in purge and trap analysis of vola- tile organic compounds. Am. Lab. 22, 38-43.

Zhang Z, Pawliszyn J. 1993. Headspace solid-phase microextraction. Anal. Chem. 65, 1843-1852.

Recibido: $13 / 6 / 12$ Aceptado: 21/8/12 